\title{
Ultraviolet Detectors Based on Wide Bandgap Semiconductor Nanowire: A Review
}

\author{
Yanan Zou ${ }^{1,2}$, Yue Zhang ${ }^{2}$, Yongming $\mathrm{Hu}^{2, *}$ and Haoshuang $\mathrm{Gu}^{2, *}$ \\ 1 School of Science, Jilin Institute of Chemical Technology, Jilin 132022, China; zyndoudou@163.com \\ 2 Hubei Key Laboratory of Ferro \& Piezoelectric Materials and Devices, Faculty of Physics and \\ Electronic Sciences, Hubei University, Wuhan 430062, China; zhangyuehb@outlook.com \\ * Correspondence: huym@hubu.edu.cn (Y.H.); guhsh@hubu.edu.cn (H.G.); \\ Tel.: +86-132-9706-9209 (Y.H.); +86-027-8866-5568 (H.G.)
}

Received: 7 May 2018; Accepted: 27 June 2018; Published: 28 June 2018

\begin{abstract}
Ultraviolet (UV) detectors have attracted considerable attention in the past decade due to their extensive applications in the civil and military fields. Wide bandgap semiconductor-based UV detectors can detect UV light effectively, and nanowire structures can greatly improve the sensitivity of sensors with many quantum effects. This review summarizes recent developments in the classification and principles of UV detectors, i.e., photoconductive type, Schottky barrier type, metal-semiconductor-metal (MSM) type, $p$ - $n$ junction type and $p-i$ - $n$ junction type. The current state of the art in wide bandgap semiconductor materials suitable for producing nanowires for use in UV detectors, i.e., metallic oxide, III-nitride and SiC, during the last five years is also summarized. Finally, novel types of UV detectors such as hybrid nanostructure detectors, self-powered detectors and flexible detectors are introduced.
\end{abstract}

Keywords: UV detectors; wide bandgap semiconductor; nanowire

\section{Introduction}

Ultraviolet (UV) detectors have received considerable attention due to their important applications in the military and civilian realms. They are used in defense warning systems, UV communication, space science, environmental monitoring, industrial production, medicine and healthcare [1-4].

UV light is a general term for a specific band of electromagnetic radiation with a wavelength range of 100-400 $\mathrm{nm}$ and energy distribution range of 3.1-12.4 eV. Figure 1 shows the common classification of UV light, which can be divided into the following bands: UVA (400-315 nm), UVB (315-280 nm), UVC (280-200 nm), and VUV (200-10 nm) [5]. When solar UV radiation passes through the ozone layer, the $240-280 \mathrm{~nm}$ wavelengths are strongly absorbed. Hence, such radiation is almost non-existent in the atmosphere near the ground, and comprises the so-called solar-blind region (SBR) [6]. In the SBR, it is easy to detect a target signal, false alarms are rarely produced, and there is little background interference. For this reason, UV detection has an advantage over infrared and laser detection technology. UV radiation in the wavelength range of 300-400 $\mathrm{nm}$ has a high penetration rate and can reach the ground, so this radiation band is called the UV window to the atmosphere.

Wide bandgap semiconductors have many useful characteristics, such as low permittivity, high breakdown electric-fields, good thermal conductivity, high electron saturation rates and radiation resistance. Hence, they can work at high temperatures, and are also ideal for developing semiconductor devices with high frequency and power, and high temperature and radiation resistance [7]. Taking III-group nitrides as an example, in terms of optical properties, their optical band gap can vary continuously from $0.77 \mathrm{eV}(\mathrm{InN})$ to $6.28 \mathrm{eV}$ (AlN), completely covering the infrared to ultraviolet band [8]. Since wide bandgap semiconductors can absorb and radiate high-energy photons, they are 
the most suitable candidates for fabricating blue, green and other short wavelength light emitting diodes (LEDs), semiconductor lasers and UV detector devices [9-12], which are widely used in the fields of optoelectronics and microelectronics.

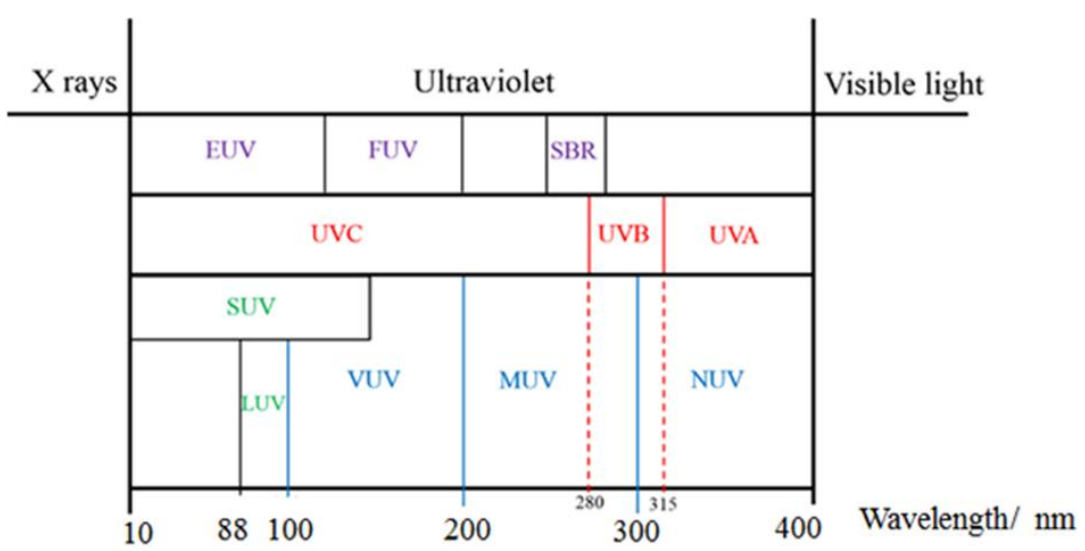

Figure 1. The classification of UV light.

In 2002, Yang and coworkers used a $\mathrm{ZnO}$ single nanowire for a UV detector and obtained an excellent UV response, setting off a stream of research into the use of one-dimensional (1D) nanomaterials for UV detection [13]. Nanowires are considered a promising building block for LEDs and sensors [14]. A large specific surface area and the presence of deep level surface trap states in nanowires greatly prolongs the photocarrier lifetime. Meanwhile, the reduced dimensionality of the active area in nanowire devices shortens the transit time of the carrier, resulting in substantial photoconductive gain $[15,16]$. In this way, photodetectors based on 1D nanowires can have excellent performance with superior sensitivity, high quantum efficiency, and fast response speed [16]. Thus, wide bandgap semiconductor nanowires are thought to be promising materials for use in optoelectronic devices [17-23], especially UV detectors or sensors [24-28].

There are few comprehensive reviews focusing on wide bandgap nanowire-synthesized UV detectors. In this article, wide bandgap semiconductor nanowire-based UV detectors are discussed in detail. First, a visual classification of UV detectors is presented. The mechanism imposed on each type of detector, as well as the inherent advantages and disadvantages of those detectors, are discussed. Recent research into materials suitable for producing nanowires for use in UV detectors and new types of UV detectors is also summarized.

\section{UV Detectors}

The classification of several typical kinds of UV detector will be introduced as follows (Figure 2): in general, UV detectors fall into two categories: vacuum and solid-state [5,29]. Vacuum UV detectors are based on different kinds of photomultiplier tubes (PMTs) and their derived imaging devices. The technology of PMT-based UV detectors is relatively mature, and it can achieve large area detection, high gain and rapid response. Unfortunately, heavy weight, low efficiency, high power consumption, fragility and high-pressure operations limit the application of vacuum UV detectors [29,30].

Solid-state UV detectors are mainly based on semiconductor materials. This article will focus on wide bandgap semiconductor nanowire materials. According to the various basic working principles, wide bandgap semiconductor UV detectors can be divided into photoconductive UV detectors and photovoltaic UV detectors [29]. Photovoltaic UV detectors also can be separated into the Schottky barrier type, metal-semiconductor-metal (MSM) type, $p-n$ junction type, and $p-i-n$ junction type. Those common schematic structures are shown in Figure 3 [31,32]. In this section, a brief description of the working mechanisms and advantages and disadvantages of each type of UV detector will be given. 


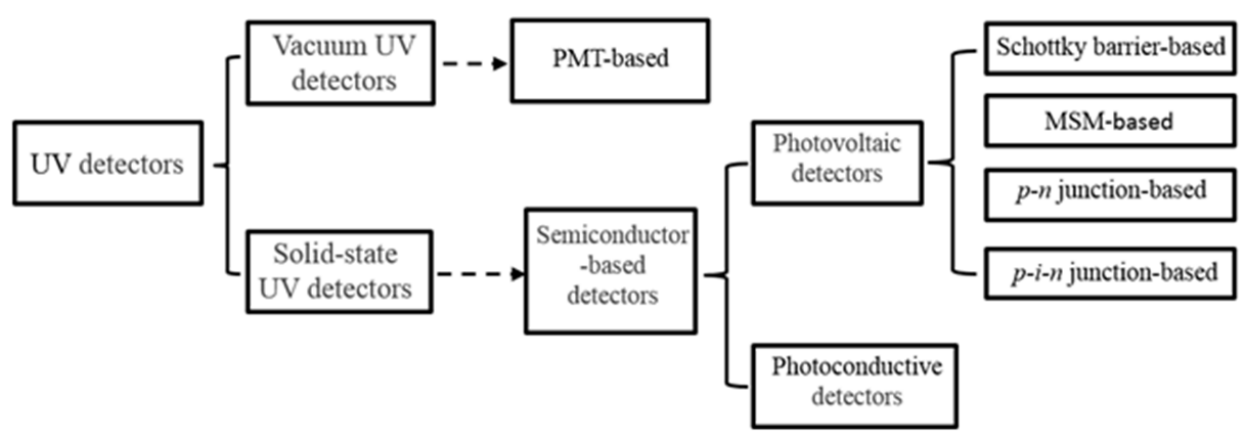

Figure 2. Classification of UV detectors.

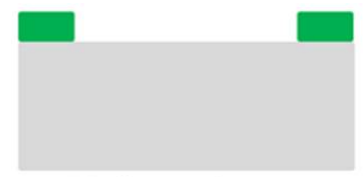

(a) Photoconductor

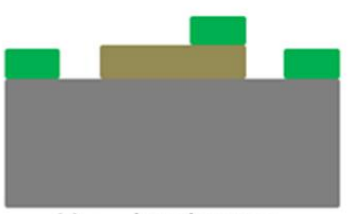

(c) $p$-n junction type

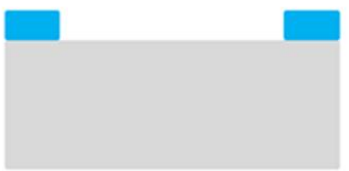

(e) MSM type

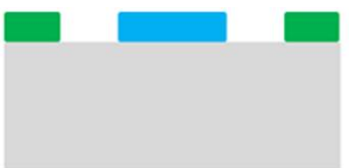

(b) Schottky barrier type

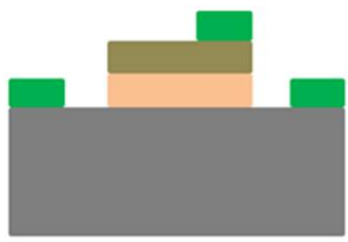

(d) $p-i-n$ junction type

Figure 3. Schematic structure of the different types of wide bandgap semiconductor UV detector.

\subsection{Photoconductive Detectors}

Photoconductive detectors, also named photoconductors, are a kind of light detector that work based on the photoconductive effect. A piece of semiconductor material and two Ohmic contacts can make up a photoconductive UV detector, as shown in Figure 3a. The operation of a photoconductor is shown in Figure 4. When a photon's energy $h v$ is greater than the band-gap energy $E_{g}$, it will be absorbed to produce an electron-hole pair, consequently changing the electrical conductivity of the semiconductor. Then, an external circuit detects the variation of electric conductivity [33,34]. Takahashi et al. [35] designed nitrogen-doped $\mathrm{ZnO}$ single crystals for use in photoconductive UV sensors. Nitrogen-doping improved significantly the photocurrent, photosensitivity, UV-visible rejection ratio, and time response of $\mathrm{ZnO}$-based UV sensors.

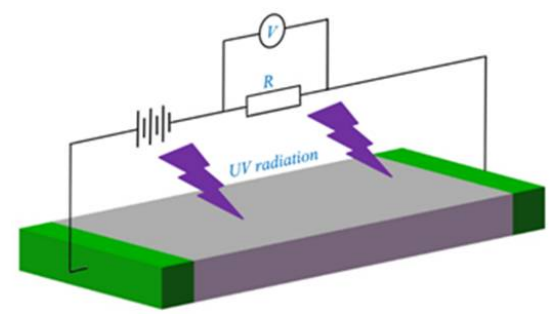

Figure 4. The operation of a photoconductor. 
Photoconductive UV detectors have simple structures, easy process control and high internal gain, but their slow response speed and large dark current remain challenging.

\subsection{Schottky Detectors}

The Schottky structure is a common structure used in wide bandgap semiconductor UV detectors. It is a Schottky diode consisting of a semitransparent Schottky contact and an Ohmic contact [36]. The schematic structure of a Schottky photodetector is shown in Figure $3 \mathrm{~b}$ and its operation is shown in Figure 5. The metal/semiconductor junctions exhibit rectifying behavior. The rectifying property of the metal-semiconductor contact arises from the presence of an electrostatic barrier between the metal and the semiconductor, which is attributed to the difference $\left(q \Phi_{b}\right)$ in the work functions of the metal and semiconductor [37]. Zhao et al. [38] fabricated an asymmetric Schottky barrier UV detector based on an $\mathrm{Ag} / \mathrm{ZnO} / \mathrm{Au}$ structure, which exhibited excellent performance. The photocurrent generated from the device under UV illumination was about $120 \mathrm{nA}$ without applying any external bias, and it also had a fast switching time of less than $30 \mathrm{~ms}$. This phenomenon was explained by using Schottky barrier and $\mathrm{O}_{2}$ adsorption-desorption theories.

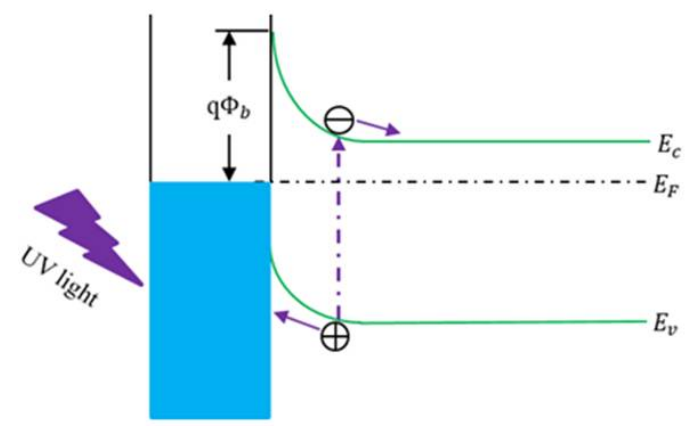

Figure 5. The schematic operation of the mental-(n-type) Schottky photoconductor.

Schottky UV detectors have many advantages, such as high responsivity, high quantum efficiency, low dark current, short response time, and possible zero-bias operations. However, for Schottky contact, the incident light should pass through the metal electrode to interact with the semiconductor (photoactive layer), so metal electrode is usually made into a very thin semi-transparent layer, while high absorption coefficient of metal electrode is a problem in Schottky detector structure. Besides, surface state effect, and shallow metal-semiconductor contact, which has restricted the development of Schottky structure UV detectors to a certain extent [36].

\section{3. $p-n$ and $p-i-n$ Junction Detectors}

A $p-n$ junction detector is a $p-n$ junction diode specifically manufactured to ensure that the detected light can penetrate into the nearby metallurgical junction. Its structure is schematically shown in Figure 3c. When light of the proper frequency irradiates the active region of the detector, a photon-generated carrier forms a photocurrent in the external circuit under an electric field, being no gain for the normal photovoltaic work mode. When forward bias is applied in the $p-n$ junction, the dark current is far greater than the photocurrent and the detector is unable to work due to unilateral conductivity characteristics. Under reverse bias, the dark current is suppressed, and moreover, the carrier transit time and diode capacitance are reduced, which are benefit to the improvement of sensitivity. [39-42]. A ZnO microwire $p$ - $n$ homojunction UV photodetector with high efficiency and high wavelength selectivity was demonstrated by Shi et al. [42]. The photodetector was formed by a single $\mathrm{Sb}$-doped $\mathrm{ZnO}$ microwire and a single undoped $\mathrm{ZnO}$ microwire.

To improve the sensitivity and response speed of devices, an intrinsic $i$ layer can be placed between the $p$ and $n$ layers to increase the width of the depletion layer, as shown in Figure $3 \mathrm{~d}$. 
In general, $p-i-n$ photodiodes work at zero bias or reverse bias (photoelectric diode mode), so that the difference between the photocurrent and dark current can reach the maximum and improve the sensitivity. With increasing reverse bias, the depletion region will be widened and the junction capacitance will be reduced, enhancing not only responsivity, but also the response speed [29]. In order to improve the performance of a $p-i-n$ device, a key factor is to increase the light transmission rate, which requires a structure designed so that light is absorbed in the depletion region. Therefore, selecting a translucent metal as the Ohmic contact and decreasing the thickness of the $p$ layer are beneficial [43]. Bugallo et al. reported a visible-blind UV photodetector based on $p-i-n$ GaN nanowire ensembles on a Si substrate [44]. The detector peak responsivity, the UV-to-visible rejection ratio, and operation speed were quite good. Their proposed technology of $p-i-n$ nanowires on Si substrates opens a path for the commercialization of efficient visible-blind detectors.

The $I-V$ characteristic of a $p-n$ photodiode is shown in Figure 6 . The total current can be expressed using the following equation [32]:

$$
I(V)=I_{S}\left[\exp \left(\frac{e V}{n k T}\right)-1\right]-e G
$$

where $I_{S}$ is the saturation current, $V$ is the applied voltage, $n$ is the ideality factor, $k$ is Boltzmann's constant, $T$ is absolute temperature and $G$ is the generation rate. $I_{S}\left[\exp \left(\frac{e V}{n k T}\right)-1\right]$ and $-e G$ correspond to the dark current and photocurrent, respectively.

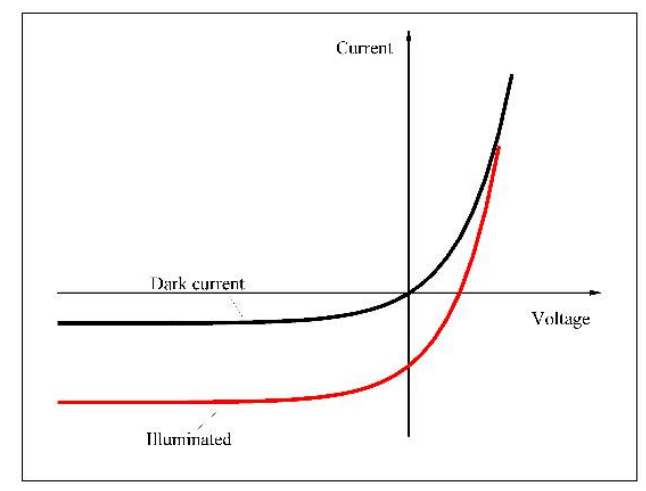

Figure 6. The $I-V$ characteristic of a $p-n$ photodiode.

The $p-n$ and $p-i-n$ photodiodes have the advantages of fast response speed, high impedance, low dark current, low or zero bias operation, capability of high-frequency operation, and compatibility of the fabrication technology with planar-processing techniques. However, their time response is usually limited by the behavior of $p$-dopants, which can also deteriorate the spectral response.

\subsection{MSM Detectors}

MSM detectors are made up of double "back-to-back" semiconductor Schottky barriers by using an inter-digitated electrode with planar linear on top of an active light collection region, as shown in Figure 7 [45,46]. Figure 3e shows its schematic structure. An MSM photodetector cannot operate at a zero bias. When under the DC bias, one of the Schottky barriers will be forward biased and the other will be reverse biased, so the dark current is quite small. Because of the low capacitance per unit area and limited transit time, MSM photodiodes also have an intrinsic rapid response ability. These devices are linear with optical power, and present a UV/visible contrast of $10^{4}$. Menzel et al. [47] reported a simple fabrication of a ZnO-nanowire-based device with applications in UV detectors, $\mathrm{pH}$ sensors, and temperature sensors. This nanowire sensor structure provides Schottky barriers due to the MSM structure. 


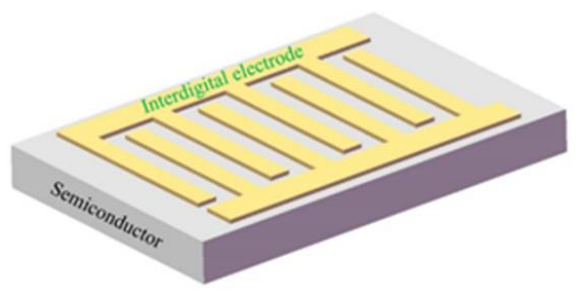

Figure 7. The schematic structure of an inter-digital electrode.

MSM detectors have a high and fast response, are little affected by bias, and have simple manufacturing processes, low cost and easy monolithic integration. However, because the metallization for the electrodes shadows the active light collecting region, it also exhibits low gain and spectral response.

\subsection{Important Parameters of UV Detector Devices}

Usually, we will choose a variety of parameters to characterize a device. Hence, some important parameters of UV detector devices are summarized as follows:

1. Cut-off wavelength: The longest wavelength $\left(\lambda_{0}\right)$ that the UV detector can detect, referring to Equation (2) [48]. It can be measured by absorption and a transmittance spectrum, where $h$ is Planck's constant, $c$ is the speed of light and $E_{g}$ is the band gap:

$$
\lambda_{0}=\frac{h c}{E_{g}}
$$

2. Photocurrent: The current formed in the external circuit. It can be tested at different biases, $I-V$ measurement under UV radiation, visible light and dark conditions.

3. Dark current: The current which remains in the detector without UV radiation. Dark current is equivalent to a noise source and will weaken the signal-to-noise ratio.

4. Time response: When the UV light turns on or off, the required time of the output value rises to become stable or decreases to the value before irradiation, accordingly. This implies the sensitivity of the device.

5. Quantum efficiency: Every incident UV photon will try to produce an electron-hole; however, the number of created electron-hole pairs is usually less than the number of photons. This represents the quantum efficiency, which can be calculated by [49]:

$$
\eta(\lambda)=R_{\lambda} \frac{h c}{q \lambda}
$$

where $R_{\lambda}$ is the measured responsivity at incident light wavelength $\lambda$, and $q$ is the electron charge.

In conclusion, high-performance UV detectors require high sensitivity, high stability and high operational speed [5]. Considering the key requirements listed above, solid-state UV detectors are more attractive than vacuum ones because they offer higher sensitivity, better linearity and higher operational speed. On the second level of Figure 2, semiconductor-based devices are chosen for their high stability, outstanding linearity, compactness and low weight. On the third level, photovoltaic detectors provide advantages both in terms of sensitivity and operational speed compared to photoconductive detectors.

\section{Materials for UV Detectors}

High performance, quantum efficiency, response speed, and signal-to-noise ratio are the most important features of UV detectors. The performance of a UV detector is mainly dependent on the inherent characteristics of the semiconductor materials used. The ability to transform optical 
signals into electrical signals is determined by a complex process of electron-hole pair generation, transportation, and recombination within the semiconductor materials. Therefore, in the next section, we will summarize wide bandgap semiconductor materials including metallic oxide, III-nitride, and $\mathrm{SiC}$. Corresponding nanowire-structured UV detectors are discussed in following sections.

\subsection{Metal Oxides}

Metal oxide materials are the focus of current research efforts since they are the commonest minerals in the earth. 1D metal oxide nanostructures have been extensively investigated for the fabrication of nanoscale photodetectors [50]. Common materials include $\mathrm{ZnO}, \mathrm{TiO}_{2}$, and $\mathrm{SnO}_{2}$; thus, in this section, we comprehensively review the above materials and introduce other metal oxides, including $\mathrm{VO}_{2}, \beta-\mathrm{Ga}_{2} \mathrm{O}_{3}$, and $\mathrm{In}_{2} \mathrm{O}_{3}$. Ternary oxides are also described.

\subsection{1. $\mathrm{ZnO}$}

$\mathrm{ZnO}$ is a direct band gap II-VI-group semiconductor material. It has strong radiation hardness, high chemical stability and is abundant. It has ionicity between covalent bonding semiconductors and ionic bonding semiconductors. At room temperature $(300 \mathrm{~K})$ and atmospheric pressure, its band gap width is $E_{g}=3.365 \pm 0.005 \mathrm{eV}$. Changes in temperature and pressure influence the width of the band gap. In addition, the exciton binding of $\mathrm{ZnO}$ is $60 \mathrm{meV}$, far higher than thermal ionization $(26 \mathrm{meV})$ under room temperature. Therefore, its excitons can remain stable at room temperature, and realize effective excitation and emission at room temperature, make them suitable for shortwave photoelectric devices [12,51-56] and a very good candidate for photonics devices working in the UV range [15,57-60]. Various methods have been used in attempts to synthesize $\mathrm{ZnO}$ nanomaterials for use in next-generation photoelectric devices. These materials include $\mathrm{ZnO}$ nanowire [61], films [62], nanorods [63,64], nanoparticles [65,66], nanobelts [67], nanowalls [68], and other hybrid structures [69].

$\mathrm{ZnO}$ nanowires have much greater photo-electronic sensitivity than $\mathrm{ZnO}$ film under UV radiation due to the nanowire carrier transport channel and much higher exciton bonding energy $[15,63]$. This results in $\mathrm{ZnO}$ nanowires being efficient in generating electron-hole pairs during UV illumination. In recent years, $\mathrm{ZnO}$ nanowires have become one of the most promising functional components for UV detectors [14,15,70-76]. Mallampati et al. [70] synthesized $\mathrm{ZnO}$ nanowires by a vapor phase transport process. Their MSM device had a responsivity in the order of $10^{5} \mathrm{~A} / \mathrm{W}$, corresponding to extremely high photoconductive gain in the order of $10^{6}$. Alsultany et al. [71] fabricated the first MSM UV photodetector based on catalyst-free growth of $\mathrm{ZnO}$ nanowire networks on indium tin oxideseeds/glass substrates by a thermal evaporation method, as shown in Figure 8. Upon exposure to $365 \mathrm{~nm}$ light $\left(1.5 \mathrm{~mW} / \mathrm{cm}^{2}\right)$ at a $5 \mathrm{~V}$ bias, their device showed sensitivity of $2.32 \times 10^{3 \%} \%$. In addition, the photocurrent was $1.79 \times 10^{-4} \mathrm{~A}$, and the internal gain of the photodetector was 24.2 . The response and recovery times were calculated as 3.9 and $2.6 \mathrm{~s}$, respectively.
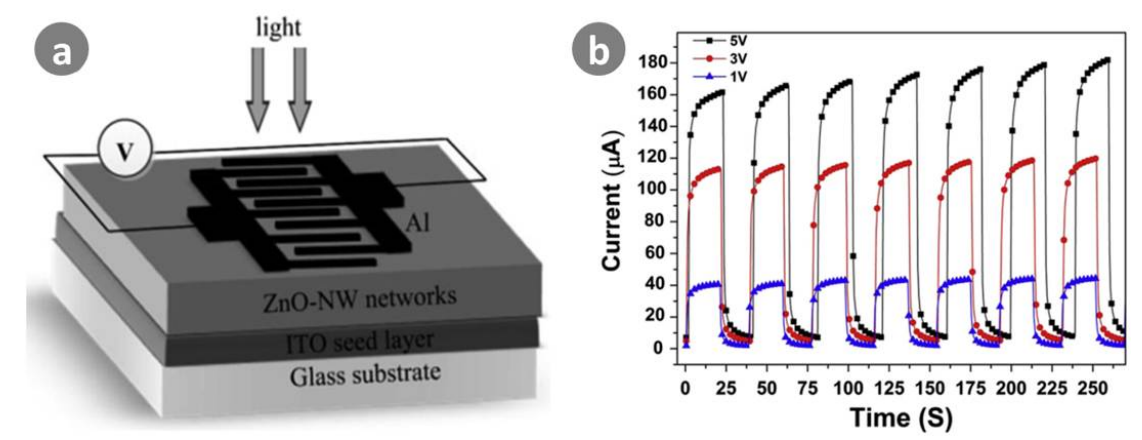

Figure 8. (a) Schematic of fabricated ZnO-nanowire networks UV photodetector; (b) Photoresponse of ZnO-nanowires UV-photodetector at various bias voltages under pulsed UV light with interval of $20 \mathrm{~s}$. Ref. [71]. Copyright 2016, Elsevier Science EV. 
$\mathrm{Li}$ et al. [72] found that the response speed and photo-to-dark current ratio of $\mathrm{ZnO}$ nanowire UV photodetectors can be optimized by tuning the entanglement and density of $\mathrm{ZnO}$ nanowires grown on $\mathrm{SiO}_{2}$ pillars through a catalyst-free chemical vapor deposition process. Their $\mathrm{ZnO}$ nanowire UV photodetector exhibited a rise time of $0.45 \mathrm{~s}$ and a decay time of $0.06 \mathrm{~s}$, with a high photocurrent to dark current ratio of $10^{2}$.

A large number of studies have investigated improvements to sensitivity and reset time. Nanophotodetectors combined with metal particles can induce plasmonics enhancement. For example, Zhao et al. [73] fabricated a ZnO nanowire-based UV photodetector with double Schottky barrier contacts using electric field guided assembly technology. Reasonable improvements were achieved by applying uniform-sized Ag nanoparticles onto the $\mathrm{ZnO}$ nanowire surfaces. As shown in Figure 9, the responsivity and photoconduction gain of the decorated device reached $4.91 \times 10^{6} \mathrm{~A} / \mathrm{W}$ and $1.67 \times 10^{7}$, respectively. The enhanced performance was associated with enhanced surface trap states and localized surface plasmon resonance effects from the uniform Ag nanoparticles. The nanoparticles played an important role in the localized gating effect, inducing dark current change in the nanoscale conductive channel.

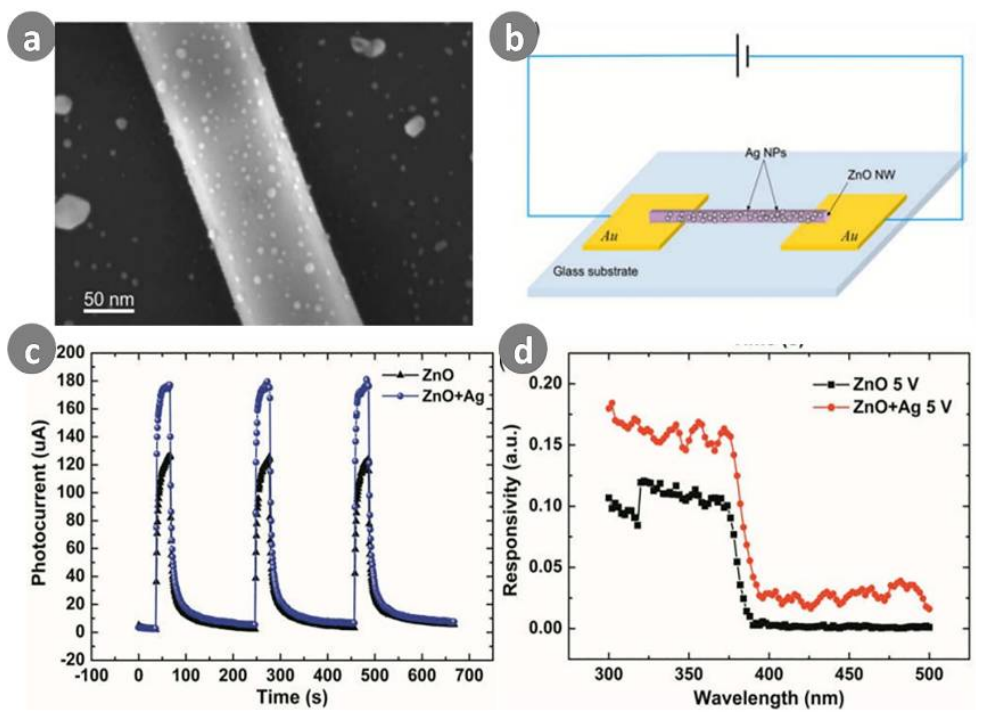

Figure 9. (a) Ag nanoparticles on the surface of $\mathrm{ZnO}$ nanowire; (b) Schematic image of the complete device with double Schottky barrier contacts; (c) Time dependence of the photocurrent under multiple on/off cycles; (d) Spectral responsivity of the devices with two type of conducting channel at $5 \mathrm{~V}$ bias. Ref. [73] Copyright 2016, Royal Society of Chemistry.

Graphene has attracted much attention in optoelectronic devices because of its excellent carrier transport mobility, high electrical conductivity, and mechanical flexibility [74]. UV photodetectors based on vertically-aligned $\mathrm{ZnO}$ micro/nanowires on graphene were prepared by Liu et al. [75], which showed a high responsivity of $1.62 \mathrm{~A} / \mathrm{W}$. Boruah et al. [76] grew a hybrid structure of $\mathrm{ZnO}$ nanowires on graphene foam for UV detection. Excellent photoresponse was obtained, with response and recovery times of 9.5 and $38 \mathrm{~s}$, respectively, and an external quantum efficiency of $2490.8 \%$.

\subsection{2. $\mathrm{TiO}_{2}$}

Titanium dioxide $\left(\mathrm{TiO}_{2}\right)$ is one of the most extensively researched materials owing to its excellent chemical stability, non-toxicity, thermal stability and low-cost. $\mathrm{TiO}_{2}$ is an n-type semiconductor with a wide band gap ranging from 3.0 to $3.2 \mathrm{eV}$ for rutile and anatase, respectively, and has great potential for application to UV detection. Different morphologies of nanostructured $\mathrm{TiO}_{2}$ have been reported for use in UV detectors, such as $\mathrm{TiO}_{2}$ films $[77,78], \mathrm{TiO}_{2}$ nanorods $[79,80]$, and $\mathrm{TiO}_{2}$ nanowires; hence, $\mathrm{TiO}_{2}$ is a promising candidate due to its unique optical and electronic properties. 
Liu et al. [81] synthesized $\mathrm{TiO}_{2}$ nanowire arrays (TNAs) with different morphologies on transparent conductive tin-doped indium oxide (ITO) and fluorine-doped tin oxide (FTO). They assembled back-incident array TNA-based UV detectors and demonstrated that single crystallographic orientation TNAs on FTO performed well. Similarly, Zhang et al. [82] synthesized vertically-oriented $\mathrm{TiO}_{2}$ nanowires on FTO-coated glass and fabricated a hybrid UV detector by spin-coating a thin layer of poly (9,9-dihexylfluorene) onto the $\mathrm{TiO}_{2}$ array. The dark current of the detector was as low as $1.9 \mathrm{nA}$ and a photoresponse peak of $568 \mathrm{~mA} / \mathrm{W}$ was obtained.

Similarly, Chen et al. [83] prepared a photodetector based on $\mathrm{TiO}_{2}$ nanowires by an inkjet printing method. The printed photodetector was highly transparent with a visible transmittance of $85 \%$ and showed a low dark current of $10^{-12}$ A with a high on/off ratio of 2000. Under a bias voltage of $2 \mathrm{~V}$, a fast rise time of $0.4 \mathrm{~s}$ was achieved, with a recovery time of $0.1 \mathrm{~s}$. Molina-Mendoza et al. [84] presented UV photodetector devices based on individual electro-spun $\mathrm{TiO}_{2}$ nanofibers transferred onto pre-patterned electrodes. As shown in Figure 10, the fabricated devices demonstrated an outstanding UV photoresponse of $\sim 90 \mathrm{~A} / \mathrm{W}$ and a response time of $\sim 5 \mathrm{~s}$.

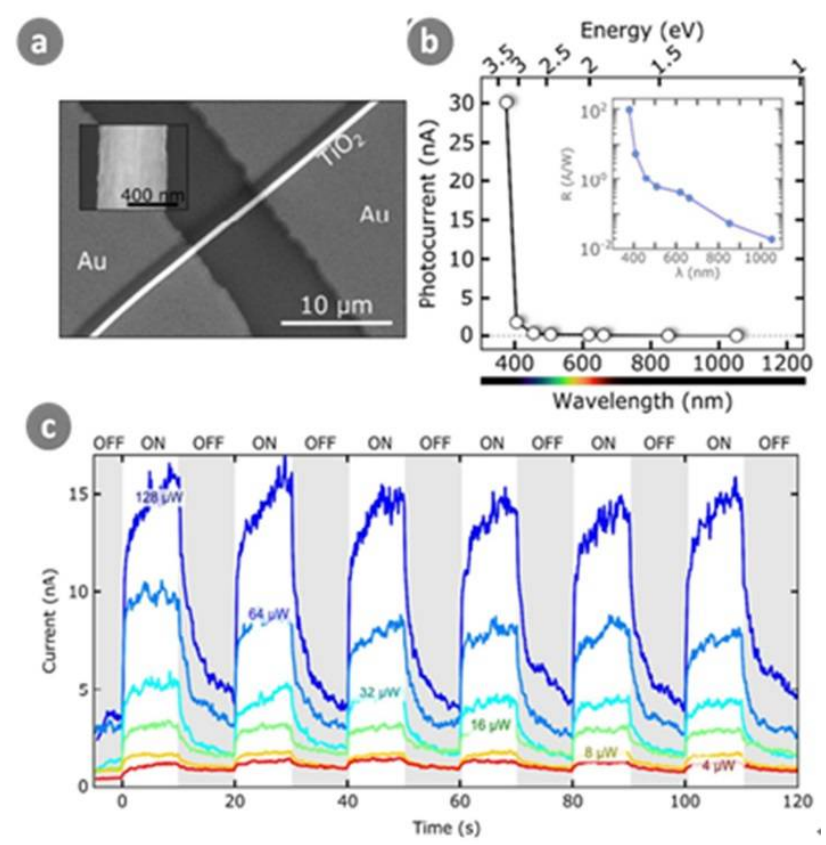

Figure 10. (a) SEM image a $\mathrm{TiO}_{2}$ fiber photodetector. Inset: zoom of the fiber; (b) Photocurrent of the device shown in (a) as a function of the LED wavelength $\left(P=2 \mu \mathrm{W}, V_{\mathrm{b}}=10 \mathrm{~V}\right)$. Inset: responsivity as a function of the LED wavelength; (c) Time response of the photodetector. In order to highlight the photocurrent, the dark current has been set to 0 . The measured rise time is $\sim 2.5 \mathrm{~s}$ and the fall time is $\sim 10$ s. Ref. [84] Copyright 2016, Royal Society of Chemistry.

\subsection{3. $\mathrm{SnO}_{2}$}

Tin dioxide $\left(\mathrm{SnO}_{2}\right)$ is an n-type oxide with a wide bandgap $\left(E_{g}\right)$ of around $3.6 \mathrm{eV}$ at room temperature. $\mathrm{SnO}_{2}$ is a useful material that can be applied as a transparent conductive oxide because of its unique optical properties and chemical stability. It is also a potential material for use in UV photodetectors. Nanostructures of $\mathrm{SnO}_{2}$ can be fabricated as nanowhiskers [85], nanobelts [86], nanorods [87-89], and nanowires [90].

$\mathrm{Hu}$ et al. [91] successfully produced thin $\mathrm{SnO}_{2}$ nanowires with a uniform diameter. Then, an individual $\mathrm{SnO}_{2}$ nanowire-based UV detector was constructed, which exhibited excellent light selectivity and stability. More importantly, a very promising characteristic of the device is its ultrahigh EQE value of $1.32 \times 10^{7}$. Via CuInS quantum dots decorated onto a single $\mathrm{SnO}_{2}$ nanowire, Lu et al. [92] successfully fabricated an ultra-high sensitivity photodetector. The gain value reached $2.5 \times 10^{5}$ 
under $325 \mathrm{~nm}$ illumination. Similarly, Lupan et al. [93] synthesized single crystalline $\mathrm{SnO}_{2}$ nanowires with $\mathrm{Zn}_{2} \mathrm{SnO}_{4}$ dots functionalized surface. The individual $\mathrm{SnO}_{2}: \mathrm{Zn}_{2} \mathrm{SnO}_{4}$ nanowire based UV photodetector exhibited photoconductive performance in terms of high response to the $375 \mathrm{~nm}$ ultraviolet light irradiation, ultra-fast response and recovery time at different temperatures $(25-300 \mathrm{~K})$.

Gan et al. [94] were the first to emphasize the important role of nanowire geometry in the improvement of photodetector performance, based on their study of a single crystalline kinked $\mathrm{SnO}_{2}$ nanowire. They demonstrated novel and simple geometry-induced high performance in a UV photodetector, as shown in Figure 11. The kinked $\mathrm{SnO}_{2}$ nanowire-based photodetector had a clear advantage over a straight $\mathrm{SnO}_{2}$ nanowire-based photodetector, both in photocurrent and photoresponse speed. Surprisingly, the photoresponsivity and EQE of the kinked $\mathrm{SnO}_{2}$ nanowire-based photodetector were ultrahigh, at $1.2 \times 10^{7} \mathrm{~A} / \mathrm{W}$ and $6.0 \times 10^{9} \%$, respectively, at most. A geometrical factor-the kinked nanowire structure-is mostly responsible for such improvement.

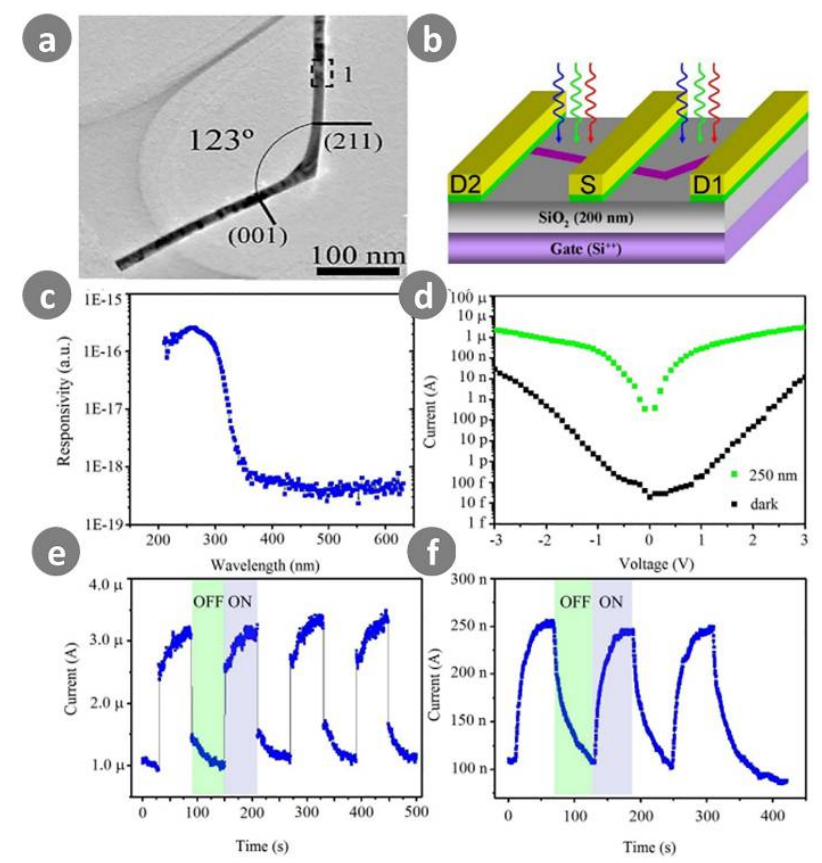

Figure 11. (a) Typical TEM image of kinked $\mathrm{SnO}_{2}$ nanowire, demonstrating the measured angle of $123^{\circ}$ between the two arms; (b) A sketch for the device composed of straight and kinked nanowire devices from a single crystalline $\mathrm{SnO}_{2}$ nanowire; (c) Spectral photoresponse measured on the kinked nanowire device (Source-Drain1) at a bias of $3 \mathrm{~V}$; (d) The comparison of photocurrent on the kinked nanowire device under 250-nm-wavelength incident light illumination (upper, green) and dark (lower, black); $(\mathbf{e}, \mathbf{f}) \mathrm{On} / \mathrm{off}$ switching test under $250 \mathrm{~nm}$ incident light illumination at a bias of $3 \mathrm{~V}$ for the kinked nanowire device and straight nanowire device (Source-Drain2), respectively. Ref. [94] Copyright 2015, Royal Society of Chemistry.

\subsubsection{Others}

In addition to the metal oxide materials mentioned above, there are other metal oxide nanowires that have been studied. Wu et al. [95] demonstrated a single microwire photodetector made using a $\mathrm{VO}_{2}$ microwire, which exhibited high responsivity and external quantum efficiency under varying light intensities. Under illumination of $1 \mu \mathrm{W} / \mathrm{cm}^{2}$, the critical UV photodetector parameters of responsivity, external quantum efficiency, and detectivity, were observed as $7069 \mathrm{~A} / \mathrm{W}, 2.4 \times 10^{10 \%}$, and $1.5 \times 10^{14}$ Jones, respectively, at a constant low bias of $4 \mathrm{~V}$. Du et al. [96] investigated a high-performance deep $\mathrm{UV}$ photodetector based on a $\beta-\mathrm{Ga}_{2} \mathrm{O}_{3}$ nanowire network. Its high sensitivity, superior selectivity, ultrafast response speed and simple fabrication technology show that $\beta-\mathrm{Ga}_{2} \mathrm{O}_{3}$ nanowire networks have potential for application in solar-blind photodetectors. The photoconductor exhibited high 
responsivity in the 200-250 $\mathrm{nm}$ range with a sharp cutoff at $270 \mathrm{~nm}$. Meng et al. [97] designed a novel photodetector based on square $\mathrm{In}_{2} \mathrm{O}_{3}$ nanowires with exposed four $\{001\}$ facets. The photodetector delivered excellent optoelectronic performance, including excellent repeatability, fast response speed, high spectral responsivity, and external quantum efficiency. The $R_{\lambda}$ and EQE values were as high as $4.8 \times 10^{6} \mathrm{~A} / \mathrm{W}$ and $1.46 \times 10^{9} \%$, respectively.

Ternary oxide nanowires are chemically and thermally stable and are superior for deep UV detection due to their large bandgap and high wavelength selectivity. Liu et al. [98] successfully fabricated a new UV-A photodetector based on a $\mathrm{K}_{2} \mathrm{Nb}_{8} \mathrm{O}_{21}$ nanowire. The single-nanowire photodetectors showed remarkable sensitivity and wavelength selectivity with respect to UV-A light. Furthermore, the photodetectors exhibited rapid response, a high discrimination ratio, robust stability, and a strong dependence of photocurrent on light intensity. Lou et al. [99] prepared $\mathrm{InGaO}_{3}(\mathrm{ZnO})$ superlattice nanowire devices on a $\mathrm{SiO}_{2} / \mathrm{Si}$ substrate. They exhibited excellent sensitivity to UV irradiation, with a spectral responsivity of $5.3 \times 10^{4} \mathrm{~A} / \mathrm{W}$, high external quantum efficiency of $1.9 \times 10^{7}$, and fast response speed of $0.3 \mathrm{~s}$. They also fabricated a photodetector using a single $\mathrm{ZnGa}_{2} \mathrm{O}_{4}$ nanowire on a $\mathrm{SiO}_{2} / \mathrm{Si}$ substrate [100]. This photodetector showed good sensitivity to UV light, and excellent properties such as high $I_{\mathrm{on}} / I_{\text {off }}$ and external quantum efficiency values, and good reversibility. Zhou et al. [101] prepared a high-performance solar-blind DUV photodetector using individual chemical vapor deposition (CVD)-fabricated $\mathrm{Zn}_{2} \mathrm{GeO}_{4}$ nanowires. The $\mathrm{Zn}_{2} \mathrm{GeO}_{4}$ nanowire-based solar-blind DUV photodetector demonstrated outstanding sensing performance, photoresponsivity of $5.11 \times 10^{3} \mathrm{~A} / \mathrm{W}$, external quantum efficiency of $2.45 \times 10^{6 \%}$, detectivity of $\approx 2.91 \times 10^{11}$ Jones, and $\tau_{\text {rise }} \approx 10 \mathrm{~ms}$ and $\tau_{\text {decay }} \approx 13 \mathrm{~ms}$.

\subsection{III-Nitride Semiconductors}

III-nitride compound semiconductors are composed of group III elements (aluminum, gallium, or indium) and the group V element (nitrogen) [2,102,103]. These include GaN, AlN, InN, and multielement alloys composed of these compounds, such as InGaN, AlGaN, and InAlGaN. III-V group materials with a wurtzite structure are direct band gap materials. By changing the alloy composition, the width of their forbidden band can be varied continuously. For AlGaN, the forbidden band can continuously change from $3.4 \mathrm{eV}(\mathrm{GaN})$ to $6.2 \mathrm{eV}$ (AlN). So, in theory, the cutoff wavelengths of a UV detector developed with intrinsic III-V materials can vary continuously between $365 \mathrm{~nm}$ and $200 \mathrm{~nm}$.

The most attractive application in the group of III-nitride semiconductor (III-V) materials is for use in blue and UV photoelectric products $[8,17,21,22,104-106]$. However, a high density of dislocations and other structural defects hinder their use. Perfect crystallization of III-V nitride nanowires demonstrates their remarkable advantage in overcoming these problems, compared to the inherent poor crystallographic quality of bidimensional (2D) layers in this material family [106].

$\mathrm{GaN}$ is the most popular semiconductor in the III-nitride material family $[17,107,108]$. Li et al. [109] fabricated nanowire-based UV photodetectors with active parts made of GaN nanowire and electrodes made of Ag nanowire networks. Via a proper thermal annealing process, the dark current and response time of the photodetector showed considerable improvement under air and vacuum conductions. Verheij et al. [110] processed radiation sensors based on GaN microwires and demonstrated capability to detect UV light and protons. The performed opto-electrical characterization revealed a fast response to irradiation with UV light. Wang et al. [111] used a nonpolar a-axial GaN nanowire constructed for an MSM symmetrical Schottky contact device for use in a visible-blind UV detector. Without any surface or composition modifications, the fabricated device demonstrated superior performance, with sensitivity as high as $10^{4} \mathrm{~A} / \mathrm{W}$ and external quantum efficiency of up to $10^{5}$, as well as an ultrafast response speed of less than $26 \mathrm{~ms}$.

Zhang et al. [112] fabricated a GaN nanowire photodetector with Pt nanoparticle modification. Great UV photoresponse was achieved; the responsivity and EQE were $6.39 \times 10^{4} \mathrm{~A} / \mathrm{W}$ and $2.24 \times 10^{7} \%$, respectively. The same year, this team improved the photoresponsivity to $1.74 \times 10^{7} \mathrm{~A} / \mathrm{W}$ 
and the EQE to $6.08 \times 10 \%$ [113]. They prepared a photodetector based on individual bicrystalline GaN nanowires, as shown in Figure 12. This also demonstrated a fast photoresponse time (144 ms), high wavelength selectivity (UV-A light response only), and a very large on/off ratio of more than two orders.

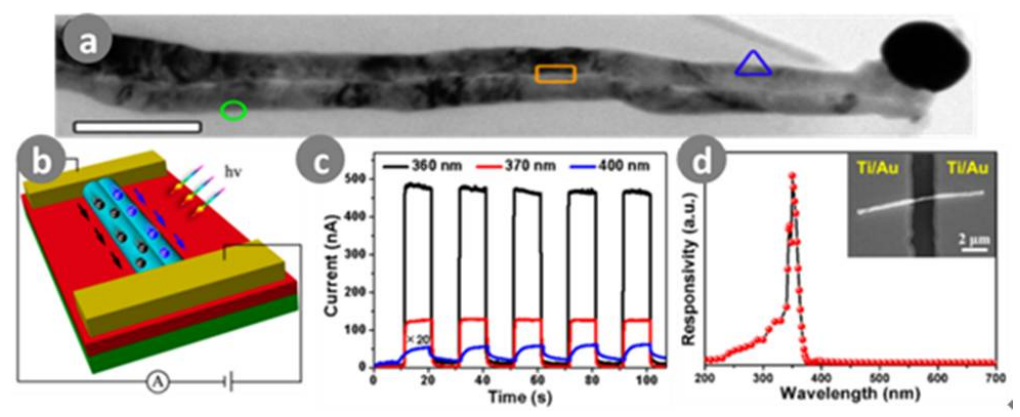

Figure 12. (a) TEM images of an single bicrystalline GaN nanowire with Ag catalyst terminated at the tip end; (b) Schematic diagram of a UV-A photodetector; (c) Under different irradiation wavelengths from 360 to $400 \mathrm{~nm}$ and a $5 \mathrm{~V}$ bias voltage and a power density of $6.41 \mathrm{~W} / \mathrm{cm}^{2}$; (d) Photoresponse curves of bicrystalline GaN nanowire UV-A photodetector as a different wavelengths ranging from 200 to $700 \mathrm{~nm}$, which is measured at a bias of 3 V. Ref. [113] Copyright 2017, American Chemical Society.

Specifically, AlN is a direct-gap semiconductor and its forbidden band is the widest among the III-V semiconductor materials [104]. This makes it an ideal preparative material for DUV/UV photoelectronic devices, and also as a new generation of information materials. Liu et al. [114] prepared ultra-long AlN nanowire arrays by CVD. The individual ultra-long AlN nanowires exhibited a clear photoconductive effect under the $325 \mathrm{~nm}$ UV wavelength. It was found that they had a fast response speed, high photocurrent response and reproductive working performance in the air environment. Zheng et al. [106] presented a two-step physical vapor transport method to grow high-quality AlN micro/nanowires. These were used to fabricate a VUV-sensitive photodetector with an ultra-short cutoff wavelength $(193 \mathrm{~nm})$, and fast photoresponse speed $(<0.1 \mathrm{~s})$ and recovery time $(<0.2 \mathrm{~s})$, as shown in Figure 13. The AlN micro/nanowire VUV photodetector showed a remarkable photocurrent increase for $\lambda<200 \mathrm{~nm}$, and its response speed was 1-2 orders of magnitude faster than the corresponding values of other reported AlN thin-film photodetectors.

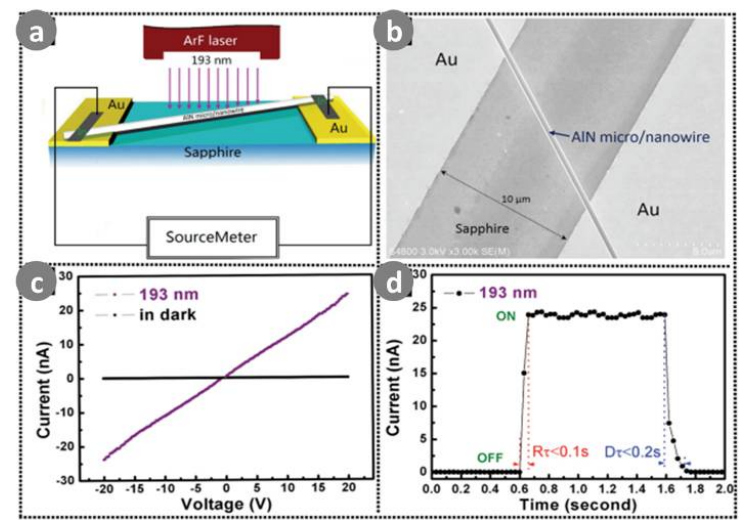

Figure 13. (a) Schematic presentation and; (b) representative SEM image of as-prepared AlN micro/nanowire-based photodetector; (c) $I-V$ characteristicsof AlN micro/nanowire-based photodetector illuminated under a light of $193 \mathrm{~nm}$ (with an average power density of $1 \mathrm{~W} \mathrm{~cm}^{-2}$ ) and under dark condition; (d) Time-dependent response of the device measured under air environment at room temperature applied a bias of 20 V. Ref. [106] Copyright 2015, Wiley. 


\section{3. $\mathrm{SiC}$}

$\mathrm{SiC}$ has different polytypes or atomic arrangements. Commercially, the most common ones are $3 \mathrm{C}-\mathrm{SiC}, 4 \mathrm{H}-\mathrm{SiC}$ and, sometimes, $6 \mathrm{H}-\mathrm{SiC}$. The latter two have hexagonal (wurtzite) structures, while 3C-SiC has a cubic zinc-blende structure. All these polytypes consist of $50 \%$ Si and $50 \% \mathrm{C}$. The difference between the hexagonal polytype is the stacking order; they are not purely hexagonal. Atomic layers in the crystal are twisted in a certain sequence, and the sequence is shorter for $4 \mathrm{H}-\mathrm{SiC}$ than $6 \mathrm{H}-\mathrm{SiC}$. Some material properties of the polytypes are listed in Table 1.

Table 1. The properties of $\mathrm{SiC}$ polytypes.

\begin{tabular}{ccccc}
\hline SiCPolytype & $\begin{array}{c}\text { Bandgap at 300 K } \\
{[\mathbf{e V}]}\end{array}$ & $\begin{array}{c}\text { Cut Off Wavelength } \\
{[\mathbf{n m}]}\end{array}$ & $\begin{array}{c}\text { Electron Mobility } \\
{\left[\mathbf{c m}^{\mathbf{2}} \mathbf{V}^{-\mathbf{1}} \mathbf{s}^{\mathbf{- 1}}\right]}\end{array}$ & $\begin{array}{c}\text { Hole Mobility } \\
{\left[\mathbf{c m}^{\mathbf{2}} \mathbf{V}^{-\mathbf{1}} \mathbf{s}^{-\mathbf{1}}\right]}\end{array}$ \\
\hline $3 \mathrm{C}$ & 2.36 & 525 & $<800$ & $<320$ \\
$4 \mathrm{H}$ & 3.23 & 384 & $<900$ & $<120$ \\
$6 \mathrm{H}$ & 3.05 & 407 & $<400$ & $<90$ \\
\hline
\end{tabular}

$\mathrm{SiC}$ is a good candidate for visible-blind UV photodetectors in high temperature, high power, and radiation-resistant applications, because of its wide band gap (2.36-3.05 eV), high breakdown electric field, high thermal conductivity, superior mechanical strength and excellent chemical stability. Accordingly, SiC-based devices can work in the harshest environments, including gaseous ones [48]. Benefiting from a large surface-to-volume ratio, long Debye length, low cost and relatively mature material technology [16], SiC nanowires can play an important role in UV detectors.

Peng et al. [48] prepared SiC nanowires by pyrolyzing a polymer precursor by a CVD route with ferrocene used as a catalyst. They fabricated UV-induced sensors based on a single such SiC nanowire. Three kinds of UV sensors based on single SiC nanowires were fabricated: with Schottky contacts, $p-n$ junction contacts, and ohmic contacts, to study dark current and photocurrent $I-V$ characteristics, photoresponse and time response properties. The results showed that the contacts between the electrode and the nanowires are important to a photodetector, the properties of which would be totally different if a different electrode fabrication process was used; for example, one which produced a different photoresponse, photocurrent, barrier and decay time. Teker [115] prepared single CVD-grown SiC nanowires. Under $254 \mathrm{~nm}$ UV light at a $2 \mathrm{~V}$ bias, a significant, positive, and fast photocurrent response was exhibited and showed great reversibility and recovery in photoconductance. The mechanism demonstrated that complete depletion of the space charge layer of the SiC nanowire enhanced the surface recombination of photoexcited electron-hole pairs.

\subsection{Conclusions}

Table 2 summarizes existing studies on nanowire-based UV detectors. Metal oxide semiconductors include $\mathrm{ZnO}, \mathrm{TiO}_{2}, \mathrm{SnO}_{2}$ and so on, all of which are very good candidates for use in photonics devices working in the UV range. Metal oxide-based UV photodetectors show good responsivity, high UV contrast ratios, high speed and low noise characteristics. In theory, the cutoff wavelengths of UV detectors developed with the intrinsic material of III-V group semiconductors can be continuously varied from $365 \mathrm{~nm}$ to $200 \mathrm{~nm}$. Specifically, the band gap width of AlN can reach $6.20 \mathrm{eV}$, making this an ideal preparative material for DUV/UV photoelectronic devices. SiC is a very good candidate for visible-blind UV photodetectors used in high temperature, high power, and radiation-resistant applications, because of its wide band gap, high breakdown electric field, high thermal conductivity and low thermal expansion properties. 
Table 2. The important parameters of UV detectors reported.

\begin{tabular}{|c|c|c|c|c|c|c|c|}
\hline Materials of Nanowires & Light (nm) & Photocurrent (A) & Dark Current (A) & Responsivity (A/W) & EQE/Gain & Response Time (s) & Reference \\
\hline $\mathrm{ZnO}$ & 370 & - & - & $10^{5}$ & $10^{8 \%}$ & & [70] \\
\hline $\mathrm{ZnO}$ & 365 & $1.79 \times 10^{-4}$ & - & - & $2420 \%$ & 3.9 & [71] \\
\hline $\mathrm{ZnO}$ & 365 & - & - & - & - & 0.45 & [72] \\
\hline $\mathrm{ZnO} / \mathrm{Ag}$ & 365 & - & - & $4.91 \times 10^{6}$ & $1.67 \times 10^{9} \%$ & - & [73] \\
\hline $\mathrm{ZnO} /$ Graphene & - & $6.3 \times 10^{-4}$ & - & 1.62 & - & 0.3 & [75] \\
\hline $\mathrm{ZnO} /$ Graphene & - & - & - & - & $2490.8 \%$ & 9.5 & [76] \\
\hline $\mathrm{TiO}_{2}(\mathrm{FTO})$ & 350 & $1.52 \times 10^{-5}$ & $3.6 \times 10^{-9}$ & 0.17 & $60.7 \%$ & & [81] \\
\hline (ITO) & & $3.37 \times 10^{-6}$ & $2.36 \times 10^{-8}$ & 0.38 & $13.4 \%$ & - & \\
\hline $\mathrm{TiO}_{2}$ & 330 & - & $1.9 \times 10^{-9}$ & $5.68 \times 10^{-1}$ & - & - & [82] \\
\hline $\mathrm{TiO}_{2}$ & - & $1.67 \times 10^{-9}$ & $2 \times 10^{-12}$ & - & - & 0.4 & [83] \\
\hline $\mathrm{TiO}_{2}$ & 375 & - & - & 90 & - & 5 & [84] \\
\hline $\mathrm{SnO}_{2}$ & 320 & $2.1 \times 10^{-6}$ & $1.94 \times 10^{-8}$ & - & $1.32 \times 10^{9} \%$ & - & [91] \\
\hline $\mathrm{SnO}_{2}$ & 325 & - & - & - & $2.5 \times 10^{7 \%}$ & - & [92] \\
\hline $\mathrm{SnO}_{2}$ & 365 & $2.3 \times 10^{-6}$ & $2.1 \times 10^{-7}$ & - & - & 0.1 & [93] \\
\hline $\mathrm{SnO}_{2}$ & 250 & - & - & $1.2 \times 10^{7}$ & $6.0 \times 10^{9} \%$ & - & [94] \\
\hline $\mathrm{VO}_{2}$ & $360-400$ & - & - & $7.07 \times 10^{3}$ & $2.4 \times 10^{10 \%}$ & 0.126 & [95] \\
\hline$\beta-\mathrm{Ga}_{2} \mathrm{O}_{3}$ & 250 & - & - & $3.77 \times 10^{2}$ & $2 \times 10^{5 \%}$ & $1.2 \times 10^{-6}$ & [96] \\
\hline $\mathrm{In}_{2} \mathrm{O}_{3}$ & 405 & $2.17 \times 10^{-2}$ & $4.5 \times 10^{-4}$ & $4.8 \times 10^{6}$ & $1.46 \times 10^{9} \%$ & 3 & [97] \\
\hline $\mathrm{K}_{2} \mathrm{Nb}_{8} \mathrm{O}_{21}$ & 320 & $1.35 \times 10^{-11}$ & $1.2 \times 10^{-12}$ & 2.53 & $982 \%$ & $<0.3$ & [98] \\
\hline $\mathrm{InGaO}_{3}(\mathrm{ZnO})$ & 350 & $4.71 \times 10^{-7}$ & $4.3 \times 10^{-9}$ & $5.3 \times 10^{4}$ & $1.9 \times 10^{9} \%$ & 0.3 & [99] \\
\hline $\mathrm{ZnGa}_{2} \mathrm{O}_{4}$ & 350 & $5.2 \times 10^{-8}$ & $4 \times 10^{-10}$ & 3.174 & $1.1 \times 10^{6 \%} \%$ & 15 & [100] \\
\hline $\mathrm{Zn}_{2} \mathrm{GeO}_{4}$ & 260 & - & $1 \times 10^{-9}$ & $5.11 \times 10^{3}$ & $2.45 \times 10^{8 \%}$ & 0.01 & [101] \\
\hline $\mathrm{GaN}$ & 325 & $10^{-8}$ & - & $2.2 \times 10^{4}$ & $3.2 \times 10^{7} \%$ & $<0.026$ & [111] \\
\hline $\mathrm{GaN} / \mathrm{Pt}$ & 380 & - & - & $6.39 \times 10^{4}$ & $2.24 \times 10^{7} \%$ & 1.1 & [112] \\
\hline GaN & $320-400$ & - & - & $1.74 \times 10^{7}$ & $6.08 \times 10^{9} \%$ & 0.144 & [113] \\
\hline AlN & 325 & - & - & $2.7 \times 10^{6}$ & - & 0.001 & [114] \\
\hline AlN & 193 & $2.4 \times 10^{-8}$ & $1 \times 10^{-14}$ & 0.39 & $254 \%$ & $<0.1$ & [106] \\
\hline SiC (Schottky) & - & $4.3 \times 10^{-6}$ & $4.3 \times 10^{-8}$ & - & - & & [48] \\
\hline $\mathrm{SiC}$ & 254 & - & - & - & - & 3 & [115] \\
\hline
\end{tabular}




\section{New Types of UV Dtectors}

\subsection{Hybrid Nanostructure UV Detectors}

Hybrid nanostructures are considered as most promising sensitive photodetection materials because they offer not only high photoconductive gain and the property benefits of 1D nanostructures, but also the added benefit of multifunctional or new properties arising from the synergistic effects of combining heterojunction materials. Chong et al. [116] successfully developed $\mathrm{TiO}_{2}-\mathrm{ZnTiO}_{3}$ heterojunction nanowire-based photodetectors and used them to detect solar-blind UV light. As shown in Figure 14, further analysis indicated that the rich existence of grain boundaries within the $\mathrm{TiO}_{2}-\mathrm{ZnTiO}_{3}$ nanowire can greatly decrease the dark current and recombination of the electron-hole pairs, and thereby significantly increase the device's photosensitivity, spectral responsivity $\left(1.1 \times 10^{6} \mathrm{~A} / \mathrm{W}\right)$, and external quantum efficiency $\left(4.3 \times 10^{8} \%\right)$.
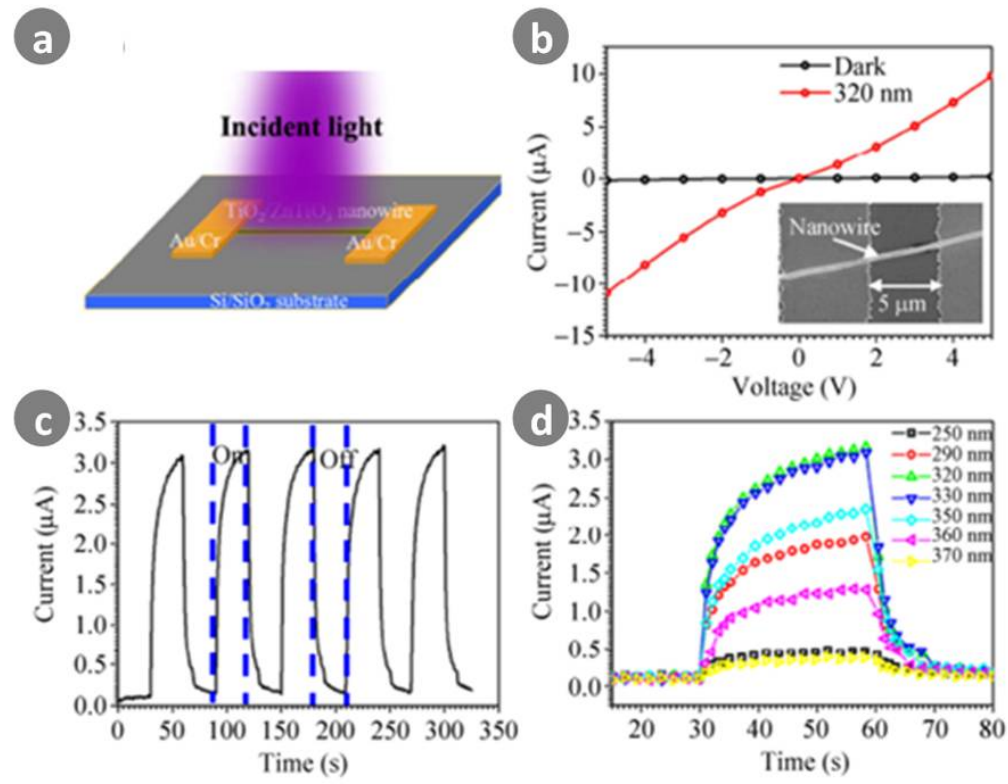

Figure 14. (a) Schematic of single $\mathrm{TiO}_{2}-\mathrm{ZnTiO}_{3}$ nanowire-based photodetector; (b) $I-V$ curves of a single nanowire-based photodetector; inset is a corresponding SEM image of the device; (c) Reproducible on/off switching illuminated by $320 \mathrm{~nm}$ light with intensity of $186.2 \mu \mathrm{W} / \mathrm{cm}^{2}$ at a bias of $2 \mathrm{~V}$; (d) Spectroscopic photoresponse of the photodetector under UV illumination under light with varying wavelengths $\left(250 \mathrm{~nm}: 208.5 \mu \mathrm{W} / \mathrm{cm}^{2}, 290 \mathrm{~nm}: 185.5 \mu \mathrm{W} / \mathrm{cm}^{2}, 320 \mathrm{~nm}: 186.2 \mu \mathrm{W} / \mathrm{cm}^{2}, 330 \mathrm{~nm}\right.$ : $191.2 \mu \mathrm{W} / \mathrm{cm}^{2}, 350 \mathrm{~nm}: 176.1 \mu \mathrm{W} / \mathrm{cm}^{2}, 360 \mathrm{~nm}: 180.9 \mu \mathrm{W} / \mathrm{cm}^{2}, 370 \mathrm{~nm}: 202 \mu \mathrm{W} / \mathrm{cm}^{2}$ ) at a bias of $2 \mathrm{~V}$. Ref. [116] Copyright 2015, Tsinhua University Press.

Recently, 1D core/shell nanostructures have been utilized in photodetectors because they have a larger specific surface area, better light-trapping effect, and longer carrier lifetime compared to pristine nanostructures. For example, self-assembled nanowires containing InGaN/GaN core/shell quantum wells were synthesized in the middle of a radial $p$ - $n$ junction by catalyst-free metal-organic vapor phase epitaxy [117]. With the same method, Zhang et al. [118] fabricated single $p$ - $n$ junction nanowire photodetectors containing 30 non-polar radial InGaN/GaN quantum well system on sapphire substrates. Rai et al. [119] fabricated a high-performance UV detector on a fully wide bandgap $\mathrm{ZnO} / \mathrm{ZnS}$ heterojunction core/shell nanowire array. Analogously, Park et al. [120] fabricated multiple networked $\mathrm{ZnO}-\mathrm{ZnS}$ core/shell nanowire photodetectors.

By adopting a vacuum-free low-cost chemical fabrication route, Dao et al. [121] fabricated a high-sensitivity UV photodetector composed of a $p-n$ heterojunction core/shell nanowire architecture using $n$-type $\mathrm{ZnO}$ and $p$-type $\mathrm{TiO}_{2}$. The device operated as a model $p$ - $n$ heterojunction with a 
linear response and sensitivity larger than $250 \mathrm{~A} / \mathrm{W}$ (5 V reverse bias, UV illumination at $373 \mathrm{~nm}$ ). Shin et al. [122] reported the formation of a $p$ - $n$ junction through the use of $\mathrm{CuO} / \mathrm{Cu}_{1-\mathrm{x}} \operatorname{In}_{\mathrm{x}} \mathrm{O}$ core/ shell nanowire structures for application in photodetectors. The fabricated core/shell $p$ - $n$ junction exhibited a photoresponsivity of $0.045 \mathrm{~A} / \mathrm{W}$ at $374 \mathrm{~nm}$.

\subsection{Self-Powered UV Detectors}

Conventional UV detectors generally need an external bias voltage as a driving force to generate photocurrent. This limits the size of the nanodevice and its independent working system. Thus, a new type of UV photodetector which operates without any power supply, namely, self-powered photodetectors, have drawn much attention. Self-powered photodetectors work at zero bias without consuming external power, hence they are more portable and adaptable than conventional photodetectors.

Generally, such self-powered photodetectors fall into two major classes according to energy conversion. One class is based on the photovoltaic effect, which can be directly driven by an optical signal, and convert light energy into electric energy through the photoelectron excitation process. The other class contains an integrated energy unit, which transforms UV radiation into electrical and chemical energy. These devices usually operate by a combination of the photoelectric and photoelectrochemical (PEC) effects.

The photovoltaic effect has huge potential for exploitation in novel self-powered UV photodetectors containing $p$ - $n$ junctions, heterojunctions, or Schottky junctions. Yang et al. [123] demonstrated the first $\mathrm{n}-\mathrm{ZnO}$ nanowire/polyaniline/ $\mathrm{ZnGa}_{2} \mathrm{O}_{4} \quad$ (a $p$ - $n$ and a type-II heterojunction)-based photodetector devices that were self-powered and had sensitivity to UV light at different wavelengths with complete current reversal capabilities. The devices also showed remarkable environmental stability. Similarly, self-powered and rapid-response p-NiO/n-ZnO nanowire UV photodetectors were fabricated and investigated using $\mathrm{Al}_{2} \mathrm{O}_{3}$ as an interface modification layer by Chen et al. [124]. A responsivity of $1.4 \mathrm{~mA} / \mathrm{W}$ was achieved under $380 \mathrm{~nm}$ UV irradiation $\left(0.36 \mathrm{~mW} / \mathrm{cm}^{2}\right)$ at zero bias, and the response time of the device was less than $0.04 \mathrm{~s}$.

Recently, progress has been made in developing a novel PEC-type self-powered photodetector, as exemplified by the work of Zhang et al. They synthesized $\mathrm{ZnO} / \mathrm{Cu}_{2} \mathrm{O}$ branched heterojunction arrays for application in photoelectrochemical-type self-powered UV-visible photodetectors [125]. At zero bias, the photodetectors based on $\mathrm{ZnO} / \mathrm{Cu}_{2} \mathrm{O}$ nanowire/electrolyte heterojunctions exhibited responsivities of $19.3 \mathrm{~mA} / \mathrm{W}$ and $8.2 \mathrm{~mA} / \mathrm{W}$ for UV and visible light, respectively, with a rise time of $0.14 \mathrm{~s}$ and a decay time of $0.36 \mathrm{~s}$. They then enhanced the self-powered photoresponse performance of the $\mathrm{ZnO}$ nanowire arrays $/ \mathrm{Cu}_{2} \mathrm{O}$ photoanodes by introducing graphene interlayers [126]. Their self-powered photodetectors based on $\mathrm{ZnO}$ nanowire arrays/graphene $/ \mathrm{Cu}_{2} \mathrm{O}$ had responsivities of $21.2 \mathrm{~mA} / \mathrm{W}$ and $17.1 \mathrm{~mA} / \mathrm{W}$ for ultraviolet and visible light, respectively, and fast rise and decay times (0.6 ms). They also designed and fabricated photoelectrochemical-type self-powered photodetectors based on patterned $\mathrm{ZnO} / \mathrm{CdS}$ nanowire arrays [127].

$\mathrm{Ni}$ et al. [128] fabricated a photoelectrochemical self-powered UV photodetector using heterostructured $\mathrm{TiO}_{2} / \mathrm{MgO}$ nanowire arrays as the photoanode. As shown in Figure 15, their UV photodetector exhibited high photocurrent density and open-circuit voltage, which was ascribed to a lower charge recombination process at the interfaces of the $\mathrm{TiO}_{2} / \mathrm{MgO}$ nanowire arrays and the electrolyte. More importantly, their UV photodetector based on $\mathrm{TiO}_{2} / \mathrm{MgO}$ nanowire arrays exhibited a remarkable responsivity of $0.233 \mathrm{~A} / \mathrm{W}$ at $365 \mathrm{~nm}$, a high on/off ratio of 14,879, a fast rise time of $0.010 \mathrm{~s}$, and a decay time of $0.011 \mathrm{~s}$ under UV irradiance, together with excellent spectral selectivity and linear optical signal response. 

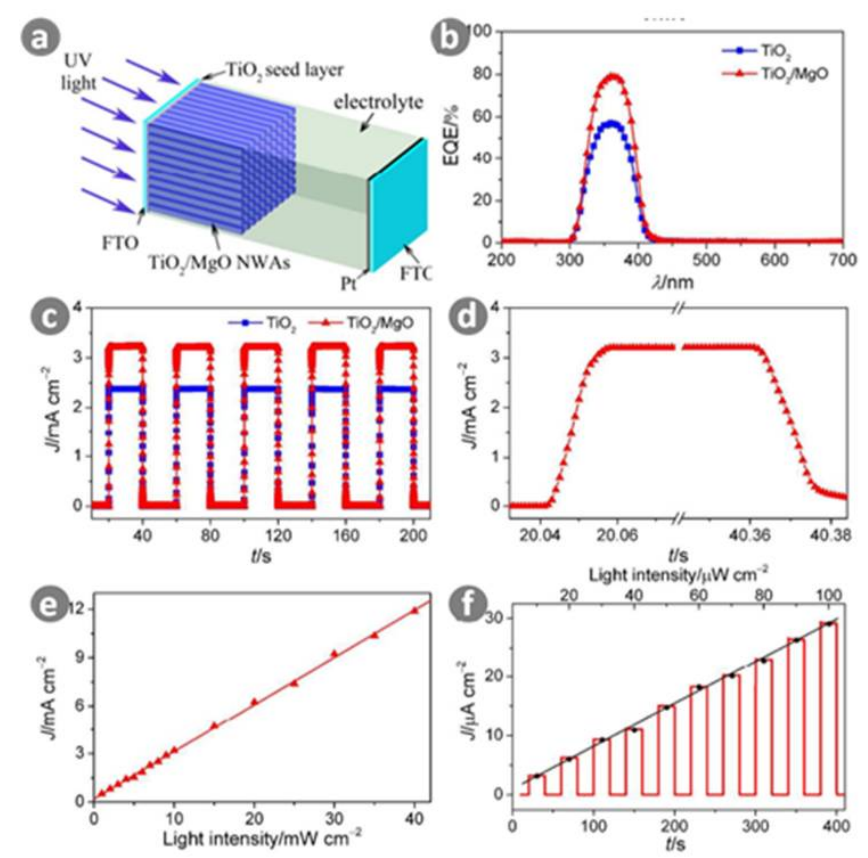

Figure 15. (a) Device structure diagram of a photoelectrochemical self-powered UV detector; (b) EQE spectra of $\mathrm{TiO}_{2}$ and $\mathrm{TiO}_{2} / \mathrm{MgO}$ nanowires based UV detectors; (c) Photocurrent responses of $\mathrm{TiO}_{2}$ and $\mathrm{TiO}_{2} / \mathrm{MgO}$ nanowires based UV detectors under on/off radiation of $10 \mathrm{~mW} / \mathrm{cm}^{2} \mathrm{UV}$ light illumination $(\lambda=365 \mathrm{~nm})$; (d) Enlarged rising and decaying edges of the photocurrent response for the $\mathrm{TiO}_{2} / \mathrm{MgO}$ nanowires based UV detectors; (e) $J$ as a function of the incident UV light intensity from 1 to $40 \mathrm{~mW} / \mathrm{cm}^{2}$ for the $\mathrm{TiO}_{2} / \mathrm{MgO}$ nanowires based UV detectors; (f) Photocurrent responses of the $\mathrm{TiO}_{2} / \mathrm{MgO}$ nanowires based UV detectors under on/off radiation of low UV light density from 10 to $100 \mu \mathrm{W} / \mathrm{cm}^{2}$. Ref. [128] Copyright 2016, Royal Society of Chemistry.

\subsection{Flexible UV Detectors}

Recently, flexible devices have become more prevalent with the aim of developing portable, wearable, lightweight and implantable optoelectronic devices. This also offers numerous opportunities for the development of next-generation UV detectors. Up to now, research on flexible UV detectors has been carried out by many groups. A flexible UV detector based on $\mathrm{SnO}_{2}$ nanowire arrays was fabricated by Kim et al. [129]. They demonstrated excellent UV sensing characteristics, demonstrating an average photosensitivity of $\sim 10^{5}$ and a photoconductive gain of $\sim 10^{6}$ under very low UV power intensities of $0.02-0.04 \mathrm{~mW} / \mathrm{cm}^{2}$. Device performance did not deteriorate with prestrain of up to $23 \%$ induced by radial deformation. Park et al. [130] proposed a new fabrication method; that of roll-to-roll processed $\mathrm{ZnO}$ nanowire-based UV photodetectors containing flexible film. A maximum photocurrent of $62.1 \mathrm{~mA}$, response time of $9.1 \mathrm{~s}$, and recovery time of $56 \mathrm{~s}$ were obtained at a bias voltage of $10 \mathrm{~V}$ under UV irradiation of $127 \mu \mathrm{W} / \mathrm{cm}^{2}$. Patel et al. [131] demonstrated a transparent and flexible photodetector using an Ag nanowire-network. Under UV illumination, remarkable performance was obtained, including quick response (rise time $=0.987 \mathrm{~ms}$, fall time $=2.49 \mathrm{~ms}$ ) and ultrahigh responsivity $\left(1.46 \times 10^{4} \mathrm{~A} / \mathrm{W}\right)$.

Zeng et al. [132] demonstrated a facile method for growing $\mathrm{ZnO}$ nanowires on polyethylene terephthalate (PET) substrates, and fabricated a flexible, self-powered UV detector. As shown in Figure 16, the assembled UV detector showed good wear-ability and flexibility. By depositing certain-sized Ag nanoparticles onto $\mathrm{ZnO}$ nanowires, the responsivity of the fabricated device was improved by $44 \%$. Such enhancement was attributed to the modified structure, which facilitates light absorption. 

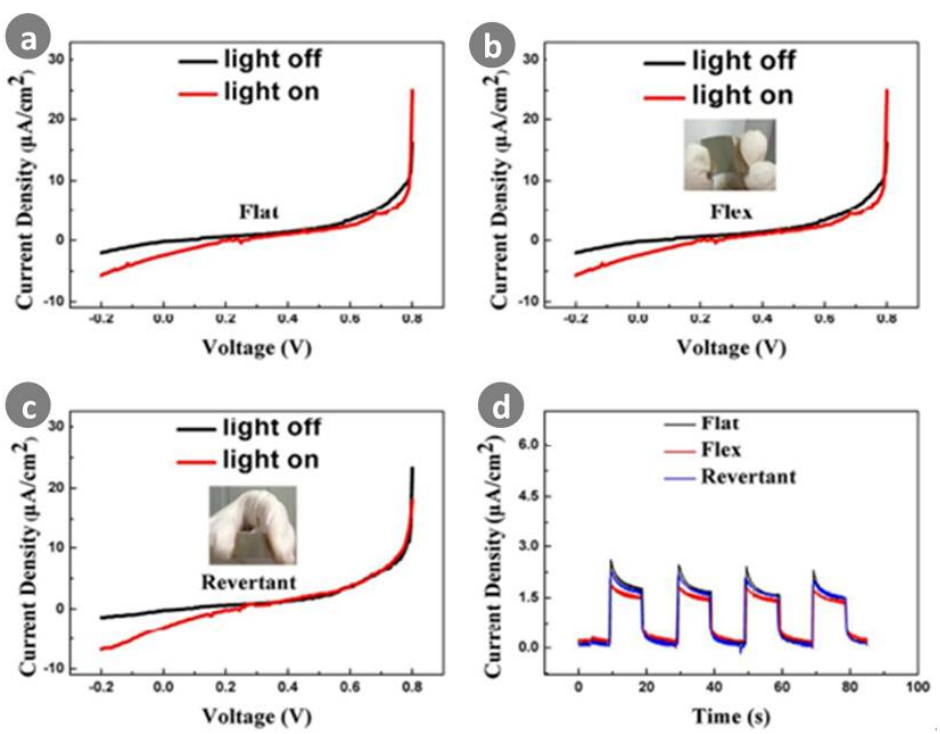

Figure 16. (a) $\mathrm{I}-\mathrm{V}$ characteristics of $\mathrm{ZnO}$ nanowires based detector (sample 1) working in the original status in darkness and under the illumination of $60 \mu \mathrm{W} / \mathrm{cm}^{2}$ of UV light $(\lambda=365 \mathrm{~nm})$; (b) I-V characteristics of $\mathrm{ZnO}$ nanowires based detector working in the bending status; (c) I-V characteristics of $\mathrm{ZnO}$ nanowires based detector working in the status after the removal of bending force; (d) Photocurrent response of $\mathrm{ZnO}$ nanowires based device in three working conditions (flat, flex, revertant) under on/off radiation of $60 \mu \mathrm{W} / \mathrm{cm}^{2}$ of UV light $(\lambda=365 \mathrm{~nm})$. Ref. [132]. Copyright 2016, Royal Society of Chemistry.

\section{Summary and Outlook}

This review summarized the various types of wide bandgap semiconductor nanowires for use in different types of UV detectors. Photoconductive UV detectors have simple structures, easy process control and high internal gain advantages, but have slow response speeds and large dark currents. In comparison, photovoltaic detectors provide advantages in terms of both sensitivity and operational speed. The photovoltaic detectors including Schottky photodiodes, $p-n$ and $p-i-n$ junction photodiodes, MSM photodetectors are discussed. Each of these different types of devices has certain advantages for UV detection, depending on the particular applications. This article also reviewed some of the important materials with nanowire structures, and their UV-detecting properties. The new types of photodetectors have gradually prompted the development of modern UV photodetectors. Fabrication of UV photodetectors based on heterostructures or nanocomposite structures will be very valuable, due to their multifunctional and property-tuning potential. Self-powered photodetectors will not only greatly enhance the adaptability of the devices, but also greatly reduce the size and weight of the systems. With the flourishing development of flexible photodetectors, great progress in portable and wearable devices will be made.

Of course, there are other UV detectors that are manufactured with infrequently-used materials, or commonly-used materials subject to unique processes; these are also worthy of consideration. Creation of a deep UV detector with high sensitivity, low noise, strong resistance to radiation, and high stability and reliability, would greatly promote the national economy and the development of aerospace enterprises. 
Author Contributions: Y.H. and H.G. conceived the manuscript; Y.Z. wrote the part of the original draft; Y.Z. wrote the paper.

Funding: This work was financially supported by the National Natural Science Foundation of China (Grant Nos. 61274073, 11474088, 11504099, 11504098), the Science and Technology Department of Hubei Province (Grant Nos. 2016AAA002, 2016CFA081) and the Key Project of Education Department in Hubei Province (D20151005).

Acknowledgments: We would like to thank Xianghui Zhang for the support of fund and the help of correcting mistakes in grammar.

Conflicts of Interest: The authors declare no conflicts of interest regarding the publication of this paper. The founding sponsors had no role in the design of the study; in the collection, analyses, or interpretation of data; in the writing of the manuscript, and in the decision to publish the results.

\section{References}

1. Delor, M.; Scattergood, P.A.; Sazanovich, I.V.; Parker, A.W.; Greetham, G.M.; Meijer, A.J.H.M.; Towrie, M.; Weinstein, J.A. Toward control of electron transfer in donor-acceptor molecules by bond-specific infrared excitation. Science 2014, 346, 1492-1495. [CrossRef] [PubMed]

2. Di, W.; Hu, Q.; Yan, Z.; Chen, W.; Yan, C.; Huang, X.; Zhang, J.; Yang, P.; Deng, H.; Wang, J.; et al. Structural basis of ultraviolet-b perception by UVR8. Nature 2012, 484, 214-219. [CrossRef] [PubMed]

3. Premi, S.; Wallisch, S.; Mano, C.M.; Weiner, A.B.; Bacchiocchi, A.; Wakamatsu, K.; Bechara, E.J.H.; Halaban, R.; Douki, T.; Brash, D.E. Chemiexcitation of melanin derivatives induces DNA photoproducts long after UV exposure. Science 2015, 347, 842-847. [CrossRef] [PubMed]

4. Chen, H.; Liu, K.; Hu, L.; Al-Ghamdi, A.A.; Fang, X. New concept ultraviolet photodetectors. Mater. Today 2015, 18, 493-502. [CrossRef]

5. Lei, S.N.S. Comparative Study of Silicon-Based Ultraviolet Photodetectors. IEEE Sens. J. 2012, 12, $2453-2459$.

6. Li, W.-D.; Chou, S.Y. Solar-blind deep-UV band-pass filter (250-350 nm) consisting of a metal nano-grid fabricated by nanoimprint lithography. Opt. Express 2010, 18, 931-937. [CrossRef] [PubMed]

7. Alaie, Z.; Mohammad Nejad, S.; Yousefi, M.H. Recent advances in ultraviolet photodetectors. Mater. Sci. Semicond. Process. 2015, 29, 16-55. [CrossRef]

8. Zhao, S.; Nguyen, H.P.T.; Kibria, M.G.; Mi, Z. III-Nitride nanowire optoelectronics. Prog. Quantum Electron. 2015, 44, 14-68. [CrossRef]

9. Ponce, F.A.; Bour, D.P. Nitride-based semiconductors for blue and green light-emitting devices. Nature 1997, 386, 351-359. [CrossRef]

10. Pengfei, T.; Ahmad, A.; Erdan, G.; Ian, M.W.; Martin, D.D.; Ran, L. Aging characteristics of blue InGaN micro-light emitting diodes at an extremely high current density of $3.5 \mathrm{kA} \mathrm{cm}^{-2}$. Semicond. Sci. Technol. 2016, 31, 045005.

11. Morkoç, H.; Strite, S.; Gao, G.B.; Lin, M.E.; Sverdlov, B.; Burns, M. Large-band-gap SiC, III-V nitride, and II-VI ZnSe-based semiconductor device technologies. J. Appl. Phys. 1994, 76, 1363-1398. [CrossRef]

12. Huang, M.H.; Mao, S.; Feick, H.; Yan, H.; Wu, Y.; Kind, H.; Weber, E.; Russo, R.; Yang, P. Room-Temperature Ultraviolet Nanowire Nanolasers. Science 2001, 292, 1897-1899. [CrossRef] [PubMed]

13. Kind, H.; Yan, H.; Messer, B.; Law, M.; Yang, P. Nanowire ultraviolet photodetectorsand optical switches. Adv. Mater. 2002, 14, 158-160. [CrossRef]

14. Bai, S.; Wu, W.; Qin, Y.; Cui, N.; Bayerl, D.J.; Wang, X. High-Performance Integrated ZnO Nanowire UV Sensors on Rigid and Flexible Substrates. Adv. Funct. Mater. 2011, 21, 4464-4469. [CrossRef]

15. Soci, C.; Zhang, A.; Xiang, B.; Dayeh, S.A.; Aplin, D.P.R.; Park, J.; Bao, X.Y.; Lo, Y.H.; Wang, D. ZnO Nanowire UV Photodetectors with High Internal Gain. Nano Lett. 2007, 7, 1003-1009. [CrossRef] [PubMed]

16. Chong, H.; Yang, H.; Yang, W.; Zheng, J.; Shang, M.; Yang, Z.; Wei, G.; Gao, F. SiC Nanowire Film Photodetectors: A Promising Candidate Toward High Temperature Photodetectors. J. Nanosci. Nanotechnol. 2016, 16, 3796-3801. [CrossRef] [PubMed]

17. Johnson, J.C.; Choi, H.-J.; Knutsen, K.P.; Schaller, R.D.; Yang, P.; Saykally, R.J. Single gallium nitride nanowire lasers. Nat. Mater. 2002, 1, 106-110. [CrossRef] [PubMed]

18. Pauporté, T.; Lupan, O.; Viana, B. Electrochemical and Hydrothermal Synthesis of Epitaxial Arrays of Doped ZnO Nanowire Emitters for Light Emitting Diodes With Tunable Emission From Near-UV to Blue. ECS Trans. 2013, 58, 17-22. [CrossRef] 
19. Eddy, C.R.; Nepal, N.; Hite, J.K.; Mastro, M.A. Perspectives on future directions in III-N semiconductor research. J. Vac. Sci. Technol. A 2013, 31, 058501. [CrossRef]

20. Yang, Z.; Wang, D.; Meng, C.; Wu, Z.; Wang, Y.; Ma, Y.; Dai, L.; Liu, X.; Hasan, T.; Liu, X.; et al. Broadly Defining Lasing Wavelengths in Single Bandgap-Graded Semiconductor Nanowires. Nano Lett. 2014, 14, 3153-3159. [CrossRef] [PubMed]

21. Arafin, S.; Liu, X.; Mi, Z. Review of recent progress of III-nitride nanowire lasers. J. Nanophotonics 2013, 7, 074599. [CrossRef]

22. Lee, S.K.; Kim, T.H.; Lee, S.Y.; Choi, K.C.; Yang, P. High-brightness gallium nitride nanowire UV-blue light emitting diodes. Philos. Mag. 2007, 87, 2105-2115. [CrossRef]

23. Pearton, S.J.; Norton, D.P.; Ren, F. The promise and perils of wide-bandgap semiconductor nanowires for sensing, electronic, and photonic applications. Small 2007, 3, 1144-1150. [CrossRef] [PubMed]

24. Li, D.; Sun, X.; Song, H.; Li, Z.; Chen, Y.; Jiang, H.; Miao, G. Realization of a high-performance GaN UV detector by nanoplasmonic enhancement. Adv. Mater. 2012, 24, 845-849. [CrossRef] [PubMed]

25. Hennessy, J.; Jewell, A.D.; Hoenk, M.E.; Nikzad, S. Metal-dielectric filters for solar-blind silicon ultraviolet detectors. Appl. Opt. 2015, 54, 3507-3512. [CrossRef] [PubMed]

26. Liu, H.; She, G.; Mu, L.; Shi, W. Porous SiC nanowire arrays as stable photocatalyst for water splitting under UV irradiation. Mater. Res. Bull. 2012, 47, 917-920. [CrossRef]

27. Oksenberg, E.; Popovitz-Biro, R.; Rechav, K.; Joselevich, E. Guided Growth of Horizontal ZnSe Nanowires and their Integration into High-Performance Blue-UV Photodetectors. Adv. Mater. 2015, 27, 3999-4005. [CrossRef] [PubMed]

28. Peng, L.; Hu, L.; Fang, X. Low-dimensional nanostructure ultraviolet photodetectors. Adv. Mater. 2013, 25, 5321-5328. [CrossRef] [PubMed]

29. Razeghi, M.; Rogalski, A. Semiconductor ultraviolet detectors. J. Appl. Phys. 1996, 79, 7433-7473. [CrossRef]

30. Lincke, R.; Wilkerson, T.D. New Detector for the Vacuum Ultraviolet. Rev. Sci. Instrum. 1962, 33, 911-913. [CrossRef]

31. Monroy, E.; Calle, F.; Pau, J.L.; Muñoz, E.; Omnès, F.; Beaumont, B.; Gibart, P. AlGaN-based UV photodetectors. J. Cryst. Growth 2001, 230, 537-543. [CrossRef]

32. Liu, K.; Sakurai, M.; Aono, M. ZnO-based ultraviolet photodetectors. Sensors 2010, 10, 8604-8634. [CrossRef] [PubMed]

33. Han, S. New developments in photoconductive detectors (invited). Rev. Sci. Instrum. 1997, 68, 647-652. [CrossRef]

34. Putley, E.H. Indium Antimonide Submillimeter Photoconductive Detectors. Appl. Opt. 1965, 4, $649-657$. [CrossRef]

35. Takahashi, S.; Abe, T.; Nakagawa, A.; Kamata, S.; Chiba, T.; Nakagawa, M.; Kashiwaba, Y.; Chiba, S.; Endo, H.; Meguro, K.; et al. Applicability of nitrogen-doped ZnO single crystals for photoconductive type UV sensors. Phys. Status Solidi C 2014, 11, 1304-1307. [CrossRef]

36. Xu, Y.; Cheng, C.; Du, S.; Yang, J.; Yu, B.; Luo, J.; Yin, W.; Li, E.; Dong, S.; Ye, P.; et al. Contacts between Twoand Three-Dimensional Materials: Ohmic, Schottky, and p-n Heterojunctions. ACS Nano 2016, 10, 4895-4919. [CrossRef] [PubMed]

37. Zahedi, F.; Dariani, R.S.; Rozati, S.M. Ultraviolet photoresponse properties of ZnO: N/p-Si and ZnO/p-Si heterojunctions. Sens. Actuators A Phys. 2013, 199, 123-128. [CrossRef]

38. Zhao, Y.; Qi, J.; Biswas, C.; Li, F.; Zhang, K.; Li, X.; Zhang, Y. Local irradiation effects of one-dimensional ZnO based self-powered asymmetric Schottky barrier UV photodetector. Mater. Chem. Phys. 2015, 166, 116-121. [CrossRef]

39. Liu, W.W.; Yao, B.; Li, B.H.; Li, Y.F.; Zheng, J.; Zhang, Z.Z.; Shan, C.X.; Zhang, J.Y.; Shen, D.Z.; Fan, X.W. $\mathrm{MgZnO} / \mathrm{ZnO}$ p-n junction UV photodetector fabricated on sapphire substrate by plasma-assisted molecular beam epitaxy. Solid State Sci. 2010, 12, 1567-1569. [CrossRef]

40. Leung, Y.H.; He, Z.B.; Luo, L.B.; Tsang, C.H.A.; Wong, N.B.; Zhang, W.J.; Lee, S.T. ZnO nanowires array p-n homojunction and its application as a visible-blind ultraviolet photodetector. Appl. Phys. Lett. 2010, 96, 53102. [CrossRef]

41. Bie, Y.-Q.; Liao, Z.-M.; Zhang, H.-Z.; Li, G.-R.; Ye, Y.; Zhou, Y.-B.; Xu, J.; Qin, Z.-X.; Dai, L.; Yu, D.-P. Self-powered, ultrafast, visible-blind UV detection and optical logical operation based on zno/gan nanoscale p-n junctions. Adv. Mater. 2011, 23, 649-653. [CrossRef] [PubMed] 
42. Shi, L.; Wang, F.; Li, B.; Chen, X.; Yao, B.; Zhao, D.; Shen, D. A highly efficient UV photodetector based on a zno microwire p-n homojunction. J. Mater. Chem. C 2014, 2, 5005-5010. [CrossRef]

43. Cai, J.; Chen, X.; Hong, R.; Yang, W.; Wu, Z. High-performance 4H-SiC-based p-i-n ultraviolet photodiode and investigation of its capacitance characteristics. Opt. Commun. 2014, 333, 182-186. [CrossRef]

44. Bugallo Ade, L.; Tchernycheva, M.; Jacopin, G.; Rigutti, L.; Julien, F.H.; Chou, S.T.; Lin, Y.T.; Tseng, P.H.; $\mathrm{Tu}, \mathrm{L} . W$. Visible-blind photodetector based on p-i-n junction GaN nanowire ensembles. Nanotechnology 2010, 21, 315201. [CrossRef] [PubMed]

45. Inamdar, S.; Ganbavle, V.; Shaikh, S.; Rajpure, K. Effect of the buffer layer on the metal-semiconductor-metal UV photodetector based on Al-doped and undoped $\mathrm{ZnO}$ thin films with different device structures. Phys. Status Solidi A 2015, 212, 1704-1712. [CrossRef]

46. Singh, $\mathrm{S}$. Al doped $\mathrm{ZnO}$ based metal-semiconductor-metal and metal-insulator-semiconductor-insulatormetal UV sensors. Opt. Int. J. Light Electron. Opt. 2016, 127, 3523-3526. [CrossRef]

47. Menzel, A.; Subannajui, K.; Güder, F.; Moser, D.; Paul, O.; Zacharias, M. Multifunctional ZnO-Nanowire-Based Sensor. Adv. Funct. Mater. 2011, 21, 4342-4348. [CrossRef]

48. Peng, G.; Zhou, Y.; He, Y.; Yu, X.; Zhang, X.A.; Li, G.Y.; Haick, H. UV-induced SiC nanowire sensors. J. Phys. D Appl. Phys. 2015, 48, 055102. [CrossRef]

49. Zhao, B.; Wang, F.; Chen, H.; Wang, Y.; Jiang, M.; Fang, X.; Zhao, D. Solar-Blind Avalanche Photodetector Based On Single $\mathrm{ZnO}-\mathrm{Ga}_{2} \mathrm{O}_{3}$ Core-Shell Microwire. Nano Lett. 2015, 15, 3988-3993. [CrossRef] [PubMed]

50. Shen, G.Z.; Chen, D. One-dimensional nanostructures for photodetectors. Recent Pat. Nanotechnol. 2010, 4, 20-31. [CrossRef] [PubMed]

51. Özgür, Ü.; Alivov, Y.I.; Liu, C.; Teke, A.; Reshchikov, M.A.; Doğan, S.; Avrutin, V.; Cho, S.-J.; Morkoç, H. A comprehensive review of zno materials and devices. J. Appl. Phys. 2005, 98, 041301. [CrossRef]

52. Yang, P.; Yan, H.; Mao, S.; Russo, R.; Johnson, J.; Saykally, R.; Morris, N.; Pham, J.; He, R.; Choi, H.J. Controlled growth of zno nanowires and their optical properties. Adv. Funct. Mater. 2002, 12, 323-331. [CrossRef]

53. Bagnall, D.M.; Chen, Y.F.; Zhu, Z.; Yao, T.; Koyama, S.; Shen, M.Y.; Goto, T. Optically pumped lasing of zno at room temperature. Appl. Phys. Lett. 1997, 70, 2230-2232. [CrossRef]

54. Repins, I.; Contreras, M.A.; Egaas, B.; DeHart, C.; Scharf, J.; Perkins, C.L.; To, B.; Noufi, R. 19.9\%-efficient $\mathrm{ZnO} / \mathrm{CdS} / \mathrm{CuInGaSe}{ }_{2}$ solar cell with 81.2\% fill factor. Prog. Photovolt. Res. Appl. 2008, 16, 235-239. [CrossRef]

55. Bai, X.; Wang, L.; Zong, R.; Lv, Y.; Sun, Y.; Zhu, Y. Performance Enhancement of ZnO Photocatalyst via Synergic Effect of Surface Oxygen Defect and Graphene Hybridization. Langmuir 2013, 29, 3097-3105. [CrossRef] [PubMed]

56. Liao, S.-H.; Jhuo, H.-J.; Cheng, Y.-S.; Chen, S.-A. Fullerene Derivative-Doped Zinc Oxide Nanofilm as the Cathode of Inverted Polymer Solar Cells with Low-Bandgap Polymer (PTB7-Th) for High Performance. Adv. Mater. 2013, 25, 4766-4771. [CrossRef] [PubMed]

57. Cheng, W.; Tang, L.; Xiang, J.; Ji, R.; Zhao, J. An extreme high-performance ultraviolet photovoltaic detector based on a ZnO nanorods/phenanthrene heterojunction. RSC Adv. 2016, 6, 12076-12080. [CrossRef]

58. Zhou, J.; Gu, Y.; Hu, Y.; Mai, W.; Yeh, P.-H.; Bao, G.; Sood, A.K.; Polla, D.L.; Wang, Z.L. Gigantic enhancement in response and reset time of zno UV nanosensor by utilizing schottky contact and surface functionalization. Appl. Phys. Lett. 2009, 94, 191103. [CrossRef] [PubMed]

59. Singh, S.K.; Hazra, P.; Tripathi, S.; Chakrabarti, P. Performance analysis of RF-sputtered ZnO/Si heterojunction UV photodetectors with high photo-responsivity. Superlattices Microstruct. 2016, 91, 62-69. [CrossRef]

60. Liang, S.; Sheng, H.; Liu, Y.; Huo, Z.; Lu, Y.; Shen, H. ZnO Schottky ultraviolet photodetectors. J. Cryst. Growth 2001, 225, 110-113. [CrossRef]

61. Das, S.N.; Moon, K.-J.; Kar, J.P.; Choi, J.-H.; Xiong, J.; Lee, T.I.; Myoung, J.-M. Zno single nanowire-based UV detectors. Appl. Phys. Lett. 2010, 97, 022103. [CrossRef]

62. Liu, Y.; Gorla, C.R.; Liang, S.; Emanetoglu, N.; Lu, Y.; Shen, H.; Wraback, M. Ultraviolet detectors based on epitaxial zno films grown by mocvd. J. Electron. Mater. 2000, 29, 69-74. [CrossRef]

63. Ji, L.W.; Peng, S.M.; Su, Y.K.; Young, S.J.; Wu, C.Z.; Cheng, W.B. Ultraviolet photodetectors based on selectively grown ZnO nanorod arrays. Appl. Phys. Lett. 2009, 94, 203106. [CrossRef]

64. Su, Y.K.; Peng, S.M.; Ji, L.W.; Wu, C.Z.; Cheng, W.B.; Liu, C.H. Ultraviolet ZnO Nanorod Photosensors. Langmuir 2010, 26, 603-606. [CrossRef] [PubMed] 
65. Liu, B.; Wang, Z.; Dong, Y.; Zhu, Y.; Gong, Y.; Ran, S.; Liu, Z.; Xu, J.; Xie, Z.; Chen, D.; et al. Zno-nanoparticle-assembled cloth for flexible photodetectors and recyclable photocatalysts. J. Mater. Chem. 2012, 22, 9379-9384. [CrossRef]

66. Chivukula, V.; Ciplys, D.; Shur, M.; Dutta, P. ZnO nanoparticle surface acoustic wave UV sensor. Appl. Phys. Lett. 2010, 96, 233512. [CrossRef]

67. Lao, C.S.; Park, M.-C.; Kuang, Q.; Deng, Y.; Sood, A.K.; Polla, D.L.; Wang, Z.L. Giant enhancement in UV response of zno nanobelts by polymer surface-functionalization. J. Am. Chem. Soc. 2007, 129, 12096-12097. [CrossRef] [PubMed]

68. Cao, B.Q.; Matsumoto, T.; Matsumoto, M.; Higashihata, M.; Nakamura, D.; Okada, T. ZnO Nanowalls Grown with High-Pressure PLD and Their Applications as Field Emitters and UV Detectors. J. Phys. Chem. C 2009, 113, 10975-10980. [CrossRef]

69. Sharma, P.; Sreenivas, K. Highly sensitive ultraviolet detector based on $\mathrm{ZnO} / \mathrm{LiNbO}_{3}$ hybrid surface acoustic wave filter. Appl. Phys. Lett. 2003, 83, 3617-3619. [CrossRef]

70. Mallampati, B.; Nair, S.V.; Ruda, H.E.; Philipose, U. Role of surface in high photoconductive gain measured in ZnO nanowire-based photodetector. J. Nanopart. Res. 2015, 17, 176-186. [CrossRef]

71. Alsultany Forat, H.; Hassan, Z.; Ahmed Naser, M. A high-sensitivity, fast-response, rapid-recovery UV photodetector fabricated based on catalyst-free growth of $\mathrm{ZnO}$ nanowire networks on glass substrate. Opt. Mater. 2016, 60, 30-37. [CrossRef]

72. Li, L.; Jiang, H.; Han, X.; Zhan, Z.; Du, H.; Lu, W.; Li, Z.; Taod, Z.; Fand, Y. Optimizing growth of ZnO nanowire networks for high-performance UV detection. Ceram. Int. 2017, 43, 15978-15985. [CrossRef]

73. Zhao, X.; Wang, F.; Shi, L.; Wang, Y.; Zhao, H.; Zhao, D. Performance enhancement in ZnO nanowire based double Shottky-Barriers photodetector by applying optimized Ag nanoparticles. RSC Adv. 2016, 6, 4634-4639. [CrossRef]

74. Bonaccorso, F.; Sun, Z.; Hasan, T.; Ferrari, A.C. Graphene Photonics andOptoelectronics. Nat. Photonics 2010, 4, 611-622. [CrossRef]

75. Liu, J.; Lu, R.; Xu, G.; Wu, J.; Thapa, P.; Moore, D. Development of a seedless floating growth process in solution for synthesis of crystalline $\mathrm{ZnO}$ micro/nanowire arrays on graphene: Towards high-performance nanohybrid ultraviolet photodetectors. Adv. Funct. Mater. 2013, 23, 4941-4948. [CrossRef]

76. Boruah, B.D.; Mukherjee, A.; Sridhar, S.; Misra, A. Highly dense ZnO nanowires grown on graphene foam for ultraviolet photodetection. ACS Appl. Mater. Interfaces 2015, 7, 10606-10624. [CrossRef] [PubMed]

77. Fu, Y.; Cao, W. Preparation of transparent $\mathrm{TiO}_{2}$ nanocrystalline film for UV sensor. Chin. Sci. Bull. 2006, 51, 1657-1661. [CrossRef]

78. Jie, X.; Huiyun, W.; Er-Jia, G.; Fang, Y. Highly sensitive fast-response UV photodetectors based on epitaxial $\mathrm{TiO}_{2}$ films. J. Phys. D Appl. Phys. 2011, 44, 375104.

79. Xie, Y.; Wei, L.; Wei, G.; Li, Q.; Wang, D.; Chen, Y.; Yan, S.; Liu, G.; Mei, L.; Jiao, J. A self-powered UV photodetector based on $\mathrm{TiO}_{2}$ nanorod arrays. Nanoscale Res. Lett. 2013, 8, 1-6. [CrossRef] [PubMed]

80. Han, Y.; Wu, G.; Wang, M.; Chen, H. Hybrid ultraviolet photodetectors with high photosensitivity based on $\mathrm{TiO}_{2}$ nanorods array and polyfluorene. Appl. Surf. Sci. 2009, 256, 1530-1533. [CrossRef]

81. Liu, G.; Zhang, M.; Zhang, D.; Gu, X.; Meng, F.; Wen, S.; Chen, Y.; Ruan, S. Effects of growth substrates on the morphologies of $\mathrm{TiO}_{2}$ nanowire arrays and the performance of assembled UV detectors. Appl. Surf. Sci. 2014, 315, 55-58. [CrossRef]

82. Zhang, M.; Li, D.; Zhou, J.; Chen, W.; Ruan, S. Ultraviolet detector based on $\mathrm{TiO}_{2}$ nanowire array-polymer hybrids with low dark current. J. Alloys Compd. 2015, 618, 233-235. [CrossRef]

83. Chen, S.P.; Retamal, J.R.D.; Lien, D.H.; He, J.H.; Liao, Y.C. Inkjet-printed transparent nanowire thin film features for UV photodetectors. RSC Adv. 2015, 5, 70707-70712. [CrossRef]

84. Molina-Mendiza, A.J.; Moya, A.; Frisenda, R.; Svatek, S.A.; Gant, P.; Gonzalez-Abad, S.; Antolin, E.; Agraït, N.; Rubio-Bollinger, G.; de Lara, D.P.; et al. Highly responsive UV-photodetector based on single electrospun $\mathrm{TiO}_{2}$ nanofibres. J. Mater. Chem. C 2016, 4. [CrossRef]

85. Luo, S.H.; Wan, Q.; Liu, W.L.; Zhang, M.; Di, Z.F.; Wang, S.Y.; Song, Z.T.; Lin, C.L.; Dai, J.Y. Vacuum electron field emission from $\mathrm{SnO}_{2}$ nanowhiskers synthesized by thermal evaporation. Nanotechnology 2004, 15, 1424-1427. [CrossRef] 
86. Comini, E.; Faglia, G.; Sberveglieria, G.; Pan, Z.; Wang, Z.L. Stable and highly sensitive gas sensors based on semiconducting oxide nanobelts. Appl. Phys. Lett. 2002, 81, 1869-1871. [CrossRef]

87. Kim, H.W.; Shim, S.H. Synthesis and characteristics of $\mathrm{SnO}_{2}$ needle-shaped nanostructures. J. Alloys Compd. 2006, 426, 286-289. [CrossRef]

88. Kim, H.W.; Lee, J.W.; Shim, S.H.; Lee, C. Controlled growth of $\mathrm{SnO}_{2}$ nanorods by thermal evaporation of $\mathrm{Sn}$ powder. J. Korean Phys. Soc. 2007, 51, 198-203. [CrossRef]

89. Liu, Y.; Zheng, C.; Wang, W.; Yin, C.; Wang, G. Synthesis and characterization of rutile $\mathrm{SnO}_{2}$ nanorods. Adv. Mater. 2001, 13, 1883-1887. [CrossRef]

90. Mathur, S.; Barth, S.; Shen, H.; Pyun, J.C.; Werner, U. Size-dependent photoconductance in $\mathrm{SnO}_{2}$ nanowires. Small 2005, 1, 713-717. [CrossRef] [PubMed]

91. Hu, L.; Yan, J.; Liao, M.; Wu, L.; Fang, X. Ultrahign external quantum efficiency from thin $\mathrm{SnO}_{2}$ nanowire ultraviolet photodetectors. Small 2011, 7, 1012-1017. [CrossRef] [PubMed]

92. Lu, M.L.; Lai, C.W.; Pan, H.J.; Chen, C.T.; Chou, P.T.; Chen, Y.F. A facile integration of zero-(I-II-VI quantum dots) and one-(single $\mathrm{SnO}_{2}$ nanowire) dimensional nanomaterials: Fabrication of a nanoconposite photodetector with ultrahigh gain and wide spectral response. Nano Lett. 2013, 13, 1920-1927. [CrossRef] [PubMed]

93. Lupan, O.; Wolff, N.; Postica, V.; Braniste, T.; Paulowicz, I.; Hrkac, V.; Kumar, Y.; Tiginyanub, M.; Kienlea, L.; Adelunga, R.; et al. Properties of a single $\mathrm{SnO}_{2}: \mathrm{Zn}_{2} \mathrm{SnO}_{4}$-Functionalized nanowire based nanosensor. Ceram. Int. 2018, 44, 4859-4867. [CrossRef]

94. Gan, L.; Liao, M.; Li, H.; Ma, Y.; Zhai, T. Geometry-induced hig performance of ultraviolet photodetectors in kinked $\mathrm{SnO}_{2}$ nanowires. J. Mater. Chem. C 2015, 3, 8300-8306. [CrossRef]

95. Wu, J.M.; Chang, W.E. Ultrahigh responsivity and external quantum efficiency of an ultraviolet-light photodetector based on a single $\mathrm{VO}_{2}$ microwore. ACS Appl. Mater. Interfaces 2014, 6, 14286-14292. [CrossRef] [PubMed]

96. Du, J.; Xing, J.; Ge, C.; Liu, H.; Liu, P.; Hao, H.; Dong, J.; Zheng, Z.; Gao, H. Highly sensitive and ultrafast deep UV photodetector based on a $\beta-\mathrm{Ga}_{2} \mathrm{O}_{3}$ nanowire network grown by CVD. J. Phys. D Appl. Phys. 2016, 49, 425105-425112. [CrossRef]

97. Meng, M.; Wu, X.; Ji, X.; Gan, Z.; Liu, L.; Shen, J.; Chu, P.K. Ultrahigh quantum efficiency photodetector and ultrafast reversible surface wettability transtion of square $\mathrm{In}_{2} \mathrm{O}_{3}$ nanowires. Nano Res. 2017, 10, 2772-2781. [CrossRef]

98. Liu, H.; Zhang, Z.; Hu, L.; Gao, N.; Sang, L.; Liao, M.; Ma, R.; Xu, F.; Fang, X. New UV-A photodetector based on individual potassium niobate nanowires with high performance. Adv. Opt. Mater. 2014, 2, 771-778. [CrossRef]

99. Lou, Z.; Li, L.; Shen, G. InGaO $\mathrm{In}_{3}(\mathrm{ZnO})$ superlattice nanowire for high-performance ultraviolet photodetectors. Adv. Electron. Mater. 2015, 1, 1500054-1500061. [CrossRef]

100. Lou, Z.; Li, L.; Shen, G. High-performance rigid amd flexible ultraviolet photodetectors with single-crystalline $\mathrm{ZnGa}_{2} \mathrm{O}_{4}$ nanowires. Nano Res. 2015, 8, 2162-2169. [CrossRef]

101. Zhou, X.; Zhang, Q.; Gan, L.; Li, X.; Li, H.; Zhang, Y. High -performance solar-blind deep ultraviolet photodetector bsed on individul single-crystalline $\mathrm{Zn}_{2} \mathrm{GeO}_{4}$ nanowire. Adv. Funct. Mater. 2016, 26, 704-712. [CrossRef]

102. Khan, M.A.; Shatalov, M.; Maruska, H.P.; Wang, H.M.; Kuokstis, E. III-Nitride UV Devices. Jpn. J. Appl. Phys. 2005, 44, 7191-7206. [CrossRef]

103. Wright, A.F. Elastic properties of zinc-blende and wurtzite AlN, GaN, and InN. J. Appl. Phys. 1997, 82, 2833-2839. [CrossRef]

104. Yong, K.-T.; Yu, S.F. AlN nanowires: Synthesis, physical properties, and nanoelectronics applications. J. Mater. Sci. 2012, 47, 5341-5360.

105. Wang, Q.; Connie, A.T.; Nguyen, H.P.; Kibria, M.G.; Zhao, S.; Sharif, S.; Shih, I.; Mi, Z. Highly efficient, spectrally pure $340 \mathrm{~nm}$ ultraviolet emission from $\mathrm{Al}_{\mathrm{x}} \mathrm{Ga}_{1-\mathrm{x}} \mathrm{N}$ nanowire based light emitting diodes. Nanotechnology 2013, 24, 345201. [CrossRef] [PubMed]

106. Zheng, W.; Huang, F.; Zheng, R.; Wu, H. Low-Dimensional Structure Vacuum-Ultraviolet-Sensitive (lambda < $200 \mathrm{~nm}$ ) Photodetector with Fast-Response Speed Based on High-Quality AlN Micro/Nanowire. Adv. Mater. 2015, 27, 3921-3927. [PubMed] 
107. Reshchikov, M.A.; Morkoç, H. Luminescence properties of defects in GaN. J. Appl. Phys. 2005, 97, 061301. [CrossRef]

108. Kim, M.-H.; Schubert, M.F.; Dai, Q.; Kim, J.K.; Schubert, E.F.; Piprek, J.; Park, Y. Origin of efficiency droop in GaN-based light-emitting diodes. Appl. Phys. Lett. 2007, 91, 183507. [CrossRef]

109. Li, P.; Meng, X. Thermal annealing effects on the optoelectronic characteristics of fully nanowire-based UV detector. J. Mater. Sci. Mater. Electron. 2016, 27, 7693-7698. [CrossRef]

110. Verheij, D.; Peres, M.; Cardoso, S.; Alves, L.C.; Alves, E.; Durand, C.; Eymery, J.; Lorenz, K. Radiation sensors based on GaN microwires. J. Phys. D Appl. Phys. 2018, 51, 175105. [CrossRef]

111. Wang, X.; Zhang, Y.; Chen, X.; He, M.; Liu, C.; Yin, Y.; Zou, X.; Li, S. Ultrafast, superhigh gain visible-blind UV detector and optical logic gates based on nonpolar a-axial GaN nanowire. Nanoscale 2014, 6, 12009-12017. [CrossRef] [PubMed]

112. Zhang, X.; Liu, Q.; Liu, B.; Yang, W.; Li, J.; Niu, P.; Jiang, X. Giant UV photorespomse of a GaN nanowire photodetector through effective Pt nanoparticle coupling. J. Mater. Chem. C 2017, 5, 4319-4326. [CrossRef]

113. Zhang, X.; Liu, B.; Liu, Q.; Yang, W.; Xiong, C.; Li, J.; Jiang, X. Ultra sensitive and highly selective photodetections of UV-A rays based on individual bicrystalline GaN nanowire. ACS Appl. Mater. Interfaces 2017, 9, 2669-2677. [CrossRef] [PubMed]

114. Liu, F.; Li, L.; Guo, T.; Gan, H.; Mo, X.; Chen, J.; Deng, S.; Xu, N. Investigation on the photoconductive behaviors of an individual AlN nanowire under different excited lights. Nanoscale Res. Lett. 2012, 7, 1-9. [CrossRef] [PubMed]

115. Teker, K. Photoresponse characteristics of silicon carbide nanowires. Microelectron. Eng. 2016, 162, 79-81. [CrossRef]

116. Chong, H.; Wei, G.; Hou, H.; Yang, H.; Shang, M.; Gao, F.; Yang, W.; Shen, G. High-performance solar-blined ultraviolet photodetector based on electrispun $\mathrm{TiO}_{2}-\mathrm{ZnTiO}_{3}$ heterojunction nanowires. Nano Res. 2015, 8, 2822-2832. [CrossRef]

117. Zhang, H.; Messanvi, A.; Durand, C.; Eymery, J.; Lavenus, P.; Babichev, A.; Julien, F.H.; Tchernycheva, M. InGaN/GaN core/shell nanowires for visible to ultraviolet range photodetection. Phys. Status Solidi A 2016, 213, 936-940. [CrossRef]

118. Zhang, H.; Guan, N.; Piazza, V.; Kapoor, A.; Bougerol, C.; Julien, F.H.; Babichev, A.V.; Cavassilas, N.; Bescond, M.; Michelini, F.; et al. Comprehensive analyses of core-shell InGaN/GaN single nanowire photodiodes. J. Phys. D Appl. Phys. 2017, 50, 484001. [CrossRef]

119. Rai, S.C.; Wang, K.; Ding, Y.; Marmon, J.K.; Bhatt, M.; Zhang, Y.; Zhou, W.; Wang, Z.L. Piezo-Phototronic Effect Enhanced UV/Visible Photodetector Based on Fully Wide Band Gap Type-II ZnO/ZnS Core/Shell Nanowire Array. ACS Nano 2015, 9, 6419-6427. [CrossRef] [PubMed]

120. Park, S.; Kim, S.; Sun, G.-J.; Byeon, D.B.; Hyun, S.K.; Lee, W.I.; Lee, C. ZnO-core/ZnSe-shell nanowire UV photodetector. J. Alloys Compd. 2016, 658, 459-564. [CrossRef]

121. Dao, T.D.; Dang, C.T.T.; Han, G.; Hoang, C.V.; Yi, W.; Narayanamurti, V.; Nagao, T. Chemically synthesized nanowire $\mathrm{TiO}_{2} / \mathrm{ZnO}$ core-shell p-n junction array for high sensitivity ultraviolet photodetector. Appl. Phys. Lett. 2013, 103, 193119. [CrossRef]

122. Shin, D.S.; Cho, I.; Kim, T.G.; Jeong, S.H.; Park, J. Investigation of $\mathrm{p}-\mathrm{CuO} / \mathrm{n}-\mathrm{Cu}_{1-\mathrm{x}} \mathrm{In}_{\mathrm{x}} \mathrm{O}$ core/shell nanowire structure performance in UV photodetectors. J. Alloys Compd. 2017, 728, 1180-1185. [CrossRef]

123. Yang, S.; Tongay, S.; Li, S.S.; Xia, J.B.; Wu, J.; Li, J. Environmentally stable/self-powered ultraviolet photodetectors with high sensitivity. Appl. Phys. Lett. 2013, 103, 143503. [CrossRef]

124. Chen, Z.; Li, B.; Mo, X.; Li, S.; Wen, J.; Lei, H.; Zhu, Z.; Yang, G.; Gui, P.; Yao, F.; et al. Self-powered narrowband $\mathrm{p}-\mathrm{NiO} / \mathrm{n}-\mathrm{ZnO}$ nanowire ultraviolet photodetector with interface modification of $\mathrm{Al}_{2} \mathrm{O}_{3}$. Appl. Phys. Lett. 2017, 110, 123504. [CrossRef]

125. Bai, Z.; Zhang, Y. Self-powered UV-visible photodetectors based on $\mathrm{ZnO} / \mathrm{Cu}_{2} \mathrm{O}$ nanowire/electrolyte heterojunctions. J. Alloys Compd. 2016, 675, 325-330. [CrossRef]

126. Bai, Z.; Liu, J.; Liu, F.; Zhang, Y. Enhanced photoresponse performance of self-powered UV-visible photodetectors based on $\mathrm{ZnO} / \mathrm{Cu}_{2} \mathrm{O}$ /electrolyte heterojunctions via graphene incorporation. J. Alloys Compd. 2017, 726, 803-809. [CrossRef]

127. Bai, Z.; Fu, M.; Zhang, Y. Vertically aligned and ordered $\mathrm{ZnO/CdS} \mathrm{nanowire} \mathrm{arrays} \mathrm{for} \mathrm{self-powered}$ UV-visible photosensing. J. Mater. Sci. 2017, 52, 1308-1317. [CrossRef] 
128. Ni, S.; Yu, Q.; Hung, Y.; Wang, J.; Li, L.; Yu, C. Heterostructured $\mathrm{TiO}_{2} / \mathrm{MgO}$ nanowire arrays for self-powered UV photodetectors. RSC Adv. 2016, 6, 85951-85957. [CrossRef]

129. Kim, D.; Shin, G.; Yoon, J.; Jang, D.; Lee, S.J.; Zi, G.; Ha, J.S. High performance stretchable UV sensor arrays of $\mathrm{SnO}_{2}$ nanowires. Nanotechnology 2013, 24, 315502. [CrossRef] [PubMed]

130. Park, J.; Lee, J.; Noh, Y.; Shin, K.H.; Lee, D. Flexible ultraviolet photodetectors with ZnO nanowire net works fabricated by large area controlled roll-to-roll processing. J. Mater. Chem. C 2016, 34, 7948-7958. [CrossRef]

131. Patel, D.B.; Patel, M.; Chauhan, K.R.; Kim, J.; Oh, M.S.; Kim, J.W. High-performing flexible and transparent photodetector by using silver nanowire-networks. Mater. Rese. Bull. 2018, 97, 244-250. [CrossRef]

132. Zeng, Y.; Pan, X.; Lu, B.; Ye, Z. Fabrication of flexible self-powered UV detectors based on ZnO nanowires and the enhancement by the decoration of Ag nanoparticles. RSC Adv. 2016, 6, 31316-31322. [CrossRef]

2018 by the authors. Licensee MDPI, Basel, Switzerland. This article is an open access article distributed under the terms and conditions of the Creative Commons Attribution (CC BY) license (http:// creativecommons.org/licenses/by/4.0/). 